\title{
Participatory governance and responsiveness: Do motivational interventions increase engagement with citizen input?
}

\author{
Annabelle S. Wittels
}

Word count: 9,881

May 30, 2021

\begin{abstract}
The idea that policies reflect the preferences of citizens is at the heart of democracy. Participatory governance was created to increase such alignment. Given how many resources governments spend on such processes, we know very little about what happens to the input. This study employs a large field experiment to test (1) whether bureaucrats tasked with policy design and implementation engage with citizen input and (2) whether bureaucrats' engagement with citizen input can be increased by using non-monetary rewards and valuebased communication. It finds low baseline engagement but that motivational interventions increase engagement with citizen input. The study contributes to theories on the role of the bureaucracy in democratic participation. Empirically, its contribution centres on testing the potential for interventions to heighten the chances of participatory governance initiatives to deliver on their normative promises.
\end{abstract}


According to Robert Dahl, central to the idea of democracy is that policies reflect the expressions of citizens' preferences (Dahl, 1989). As Verba et al. (1995) stress, elections do not suffice for citizens to express their full range of preferences and needs. Participatory governance initiatives have been created to provide more direct channels of communication between the electorate and government. They can provide avenues for typically underrepresented groups to voice their concerns. Participatory governance initiatives are government initiated and citizens are asked to express their opinions on a defined and compared to election manifestos - more immediate set of policy actions. They present a more top-down form of participation than other forms of citizen engagement such as participation in social movements. This renders citizens dependent on faithful management of their input in order to achieve impact on policy.

Participatory governance has held the promise of "deepening" democracy by increasing citizens' engagement with policy debates and involving them throughout the policy-making cycle (Fung, 2006). Participatory governance takes a variety of forms - ranging from surveys, stakeholder consultations, deliberative fora such as citizen juries to citizen-led budgeting processes, so-called participatory budgeting. Often multiple forms of participation are combined and information condensed to provide briefs used in policy planning and implementation. Governments expend considerable effort and resources to run participatory processes (OECD, 2009; Speer, 2012). Yet, it remains largely unclear to what extent such processes deliver on their promise. 
Existing evidence mostly relates to the experience of citizens (Lowndes et al., 2001; Irvin and Stansbury, 2004; Michels, 2011; Herian et al., 2012). Citizens' political awareness, confidence and trust in government increases as a result of partaking in participatory governance initiatives (Irvin and Stansbury, 2004). Much less information is available on what happens to the input gathered through participatory processes (Ebdon and Franklin, 2006); how is it handled and might this explain deficiencies in responsiveness?

While there is evidence that participatory governance initiatives positively affect political knowledge and engagement (Irvin and Stansbury, 2004: John, 2009; Yang and Pandey, 2011; Kroll et al., 2019; Migchelbrink and Van De Walle, 2020), it appears to have little to no effects on policy output (Irvin and Stansbury, 2004, Boulding and Wampler, 2010; Guo and Neshkova, 2012; Geissel, 2009; Cohen et al., 2016).

Often, there is political will lacking to follow through on demands (Irvin and Stansbury, 2004, Geissel, 2009). However, when there is political will, throughput is still not guaranteed. Citizens' input needs to be collected, condensed and processed into actionable directives - processes that bureaucrats manage. Bureaucrats can shape policy output by delaying execution and amending details of execution. Where political salience is low or there is a high demand for technical expertise, bureaucrats can also influence policy more directly as they are granted greater control over policy design (Page, 2012).

What bureaucrats implement is theorised to be a mixture of following 
political directives, their personal beliefs (Prendergast, 2007) and professionalised norms (Migchelbrink and Van De Walle, 2020). Thus, values and motivations that bureaucrats hold could be significant drivers of whether citizen input receives the attention that is promised by participatory initiatives (Meier and O'Toole, 2006, Yang and Callahan, 2007; Yang and Pandey, 2011).

However, whether and how bureaucrats do so remains unclear. There are thus gaps in how we theorise the role of bureaucrats in the context of processes that promise to deliver an improved form of democracy (Fung, 2006). Existing literature provides suggestive evidence that motivations and values shape whether bureaucrats pay attention to what citizens want (Yang and Callahan, 2007); yet, so far no clear causal relationship has been established. This is problematic for public policy practitioners: considerable resources are spent on participatory governance and it is recommended as the "gold standard" for government-initiated engagement between elections; yet evidence of its efficacy is largely lacking (OECD, 2009).

This paper sets out to systematically test this using a field experiment in a local authority in England which randomises how citizen input is presented to bureaucrats employed in the authority. It first asks whether access to the policy-making process granted through participatory initiatives is malleable to bureaucrat motivation, and second, whether certain tactics of public management could increase bureaucrat motivation to deliver on the promise of responsiveness to citizen voice. Findings show that without intervention, few 
bureaucrats pay attention. Only about a third open emails containing relevant information and no one $(0 \%)$ follows through to consult materials that provide necessary information for their area of work. The rate of engagement markedly increased when motivation-based interventions were used. When value-based messages were used, $15 \%$ of targeted bureaucrats engage with the information and $14 \%$ when a "thank-you" message is used.

This study contributes by linking up theories of participatory democracy and public administration. It showcases how bureaucrats can affect the potential for participatory governance to deliver on their normative promises: to provide greater access to decision-makers and feed more directly into the policy-making process. Empirically, this study showcases how such obstacles can be removed and engagement with citizen input increased.

\section{Why bureaucrats matter for participatory governance}

How bureaucrats handle citizen input from participatory governance initiatives is central to the question whether participatory governance can live up to its normative promise of "deepening democracy". Even when citizen input does not directly affect policy, the access responsiveness that bureaucrats provide is crucial (Schneider, 1999): when those who design policy and implementation plans do not consider citizen input or choose to remain unaware of it, the power over policy decisions that participatory governance grants citizens becomes void. Different to situational responsiveness of street-

level bureaucrats who might receive verbal feedback from a citizen unfiltered, 
bureaucrats employed in planning and policy design functions need to rely on aggregated forms of information. In these settings, how citizen input is presented can substantially affect its potential to influence decisions of bureaucrats and policy-makers.

In many instances, citizens might lack the technical knowledge necessary to make a convincing demand or lack the social connections to form necessary alliances with more powerful stakeholders. In such situations, their efforts are likely to go wasted - participatory governance becomes a show without concrete effects (Irvin and Stansbury, 2004). Bureaucrats can mobilise resources necessary to make policy proposals more appealing to political principals and other important stakeholders. On the other hand, when citizen input is captured by lobbies unrepresentative of the interests of the larger population, bureaucrats play a crucial role in discounting such information and preventing it from gaining undue influence over the policy process. This is especially relevant in contexts where a technocratic bureaucracy provides a bulwark against potentially undemocratic tendencies and policy-making dominated by political campaigning (Miller and Whitford, 2016).

This function might gain greater importance as populist leaders increase their reliance on participatory governance to justify partisan policies. For instance, in the U.S. Donald Trump used a citizen survey in 2018 to ask the public "Do you feel the mainstream media is actively working against the Trump Administration?" (Trump Headquarters, 2018), in order to bolster his arguments for curtailing press freedoms. Perhaps one of the most prolific 
abusers of participatory governance in recent times is the government of Victor Orban which launched more than a dozen national citizen consultations in the last decade (Batory and Svensson, 2019).

Currently available evidence suggests that the democracy-enhancing effects of participatory governance initiatives are highly limited or completely lacking. Cohen et al. (2016) conclude that while some concerns find reflection in policy, they are generally subordinate to financial constraints. Geissel (2009) presents an in-depth study of "Local Agenda 21", a system used by German local governments, aimed at creating sustainable local development by involving citizens in the design process of local policy. She concludes that while citizens gain greater political awareness and social connections to others, throughput is highly limited and changes in actual outputs are the exception rather than the rule. Font et al. (2018) review 571 instances of citizen-led policy proposals in Spain from 2007-2011 and find that citizen power is limited by institutional constraints - initiatives fail to redress existing power imbalances. Yet, John (2009) finds that in the UK in the early to mid 2000s participatory initiatives attracted younger and more female citizens who would otherwise be underrepresented in more traditional forms of civic engagement such as writing to their MPs.

While this could have helped to address bias in existing forms of citizen input, participatory initiatives remained highly unrepresentative of local and national populations alike. Even the most involved form of citizen participation - participatory budgeting, where citizens are consulted over a long 
period of time and have direct voting power over parts of local budgets - yield few positive results (Peixoto et al., 2020). Boulding and Wampler (2010) find that citizen participation is associated with greater spending on health and social policy but that the effectiveness of policies does not change.

Instances where citizen input is found to have impact heavily rely on self-reports of citizens and administrators (Irvin and Stansbury, 2004; Yang and Callahan, 2007; Yang and Pandey, 2011), or struggle to disentangle qualities of bureaucrats from the impact of citizen input. For instance, Guo and Neshkova (2012) find that transport departments that use citizen input achieve a better efficiency and effectiveness ratio in their policy output than those that do not use citizen input.

Unfortunately, methods that these papers employ however do not allow us to robustly distinguish between the effects of context, individual differences and the effects of citizen input. For instance, in Guo and Neshkova (2012), those departments that use citizen input for policy-making might also attract more skilled bureaucrats or have more socially engaged and compliant populations who speed less, thereby affecting the efficiency/effectiveness ratio. Similar factors could be at play in the study run by Kroll et al. (2019) who finds that departments that have performance-monitoring in place use citizen input to a greater degree.

Institutional and political constraints are key (Font et al., 2018; John, 2009; Irvin and Stansbury, 2004) but individual biases of the bureaucrats handling participatory processes matter too. 
Evidence suggests that bureaucrats are more responsive to input that they perceive as more representative of relevant stakeholder groups (John, 2009, Migchelbrink and Van De Walle, 2020). Representativeness is however not an objective quantity. It might entail hearing from a broad range of usually under-represented constituent groups or it might be statistical representativeness which reflects the general demographic make-up of areas concerned by the policy, or even more broadly the electoral wards of their political principals. To what extent bureaucrat judge input as representative empowers some and disempowers other groups. While the perceived quality of input appears to matter, bureaucrats can cherry-pick input by emphasising what they agree with and discounting the value of what they see as unwelcome input (Font et al., 2018).

Due to the technical, labour intensive nature of policy-making and the sheer impossibility of regulating all actions necessary to deliver policy, bureaucrats have considerable discretion of what feeds into policy and how policy is adapted in the implementation process. The next section discusses strategies that could be used to increase the likelihood of bureaucrats acting as enablers rather than barriers to citizen input feeding through into policy as promised by participatory governance initiatives. 


\section{What motivates bureaucrats to engage with citizen in- put?}

Incentives for bureaucrats to respond to citizen input can broadly be classified in two categories:(i) value-based and belief-based consideration and (ii) career- and process-based considerations. Different to politicians, who have electoral incentives to respond to citizen demands, bureaucrats are expected to do so because participatory governance initiatives support democratic values. They are politically and legally legitimate mechanisms for citizens to access policy processes outside the electoral cycle. If bureaucrats believe that being responsive to citizen concerns aligns with their mandate to serve the public, they should be motivated to engage with citizen input. Such motivations will be strengthened when bureaucrats private beliefs align with the principle of participatory governance: local citizens should be provided voice over local policy issues [see (Prendergast, 2007, Bertelli and Feldmann, 2007)].

The second set of incentives is linked to considerations relating to the rules by which bureaucrats need to play as part of a professionalised bureaucracy: participatory governance initiatives come with certain procedures that should be followed. For instance, most public administrations require that results of citizen surveys, consultations and participatory budgeting processes are published and publicly available. More recently, this has been extended to include having to report on how administrations have acted upon the 
results of these exercises. Senior management thus has an incentive to get other bureaucrats (their staff) to respond to input. Bureaucrats on the other hand are incentivised to respond as this reflects positively on their work performance and might help them to progress in their career in the long-run.

The next section discusses these two sets of incentives and interventions targeted at tapping into them in more detail. In addition to these incentives, it discusses an alternative theory which could explain a lack of responsiveness and how to disentangle lack of motivation from a lack of capacity to respond.

\section{Public sector values}

Work on bureaucracy has focused on questions of personnel selection. In this line of logic, choosing the people with the right set of skills and motivations should lead to more efficient and effective delivery of public services [e.g. see Bertelli (2012) for a more in-depth discussion]. However, bureaucrats performance can change with age and tenure, even when there is no reform to public management (Esteve and Schuster, 2019). Thus, not personal characteristics but sets of values and motivations might be a better predictor of engagement. It has been posited that bureaucrats might possess a certain type of motivation, public service motivation, which is a more stable set of traits that predicts performance in the absence of monetary rewards.

Public service motivation is a set of values that encourages expending effort to provide high quality services to the public, usually in absence or unresponsive to monetary incentives (Perry, 2015). Public service motivation 
is central to understanding to what extent bureaucrats will engage with concerns of the public. Yang and Callahan (2007), for example, find in a survey of U.S. public administrators that they respond more to participatory input when they value citizen input. Further, departments that have a citizenor client-orientation are also more receptive to input. It is plausible that when citizen input highlights key values of bureaucrats they are more likely to engage with participatory input. However, since studies such as Yang and Pandey (2011) are forced to rely on self-reports, it is unascertained whether links are due to social desirability and whether such correlations would hold if we looked at actual use (a behavioural measure) instead of self-reported behaviour. Further, it remains unclear whether a causal relationship exists: do the values bureaucrats hold lead them to respond to citizen input to a greater degree when it reflects these values?

In economics values have been recognised as factors key to understanding the behaviour of individuals and groups. Values shape other- and processregarding behaviours alongside more classically rational, purely selfish behaviours (Ben-Ner and Putterman, 1998). Research on public service motivation suggests that bureaucrats might be particularly inclined to act in the interest of the public because of certain values they hold (Meier and O'Toole, 2006; Perry, 2015; Ritz, 2015; Tummers and Bekkers, 2014). Research from organisational and clinical psychology, which suggest that seeing an explicit link between one's values and one's work can improve motivation and performance - a finding that holds true across industries and geographical contexts 
(Maricutoiu et al., 2016). It appears plausible that highlighting the link between engaging with citizen input and values that bureaucrats hold could increase their motivation.

\section{Symbolic rewards}

Bureaucrats, like private sector workers, also respond to extrinsic rewards such as pay for performance Andrews and Esteve, 2015; Esteve and Schuster, 2019). However, in the public sector, the scope for monetary incentives is limited. Non-monetary rewards, typically called "symbolic rewards" in the economics literature, are more easily available. They are hypothesised to affect motivation through social recognition of performance.

Symbolic rewards have been employed across settings and seen promising results. For instance, Panagopoulos (2011) found that one of the simplest forms of a symbolic reward, a "thank you" message, could increase turnout in three separate U.S. elections. Such behaviour does not appear to be limited to the electoral context. It has also been observed in a variety of organisational settings Grant et al., 2007; Bradler and Neckermann, 2016; Gallus, 2015; Bellé, 2015; Bovaird and Löffler, 2009; Ashraf et al., 2014) 1]

\footnotetext{
${ }^{1}$ In the context of asking bureaucrats to engage with citizen input from participatory activities, symbolic rewards could be motivating mainly in two ways: they could be rewarding in an of itself (provide the "warm, fuzzy feeling") or they could signal social recognition and associated career prospects ("co-workers or superiors believing that they did well").
} 


\section{Cognitive capacity}

Motivation can however only affect performance if there is enough cognitive capacity left to deploy. Even the most committed and driven bureaucrat is limited by their cognitive abilities. In the context of budget cuts to government services, fewer staff has to deal with a greater number and variety of requests. If bureaucrats do not have the time and cognitive resources to read through a lot of information, the effect of improving motivation will be limited at best. Instead, reducing the time and cognitive resources it takes to process information could increase the rate at which bureaucrats engage with it. Cognitive load theory predicts that if information load exceeds the available bandwidth, motivation no longer has an effect as there are simply too few cognitive resources available to perform the task or more of the task. When information load is low, on the other hand, more bandwidth would be available to perform tasks (Moreno and Park, 2010, p.10). Based on this, it could be expected that if citizen input is condensed, so that it is quicker and easier to engage with, bureaucrats should be more likely to engage with the information.

The next section describes an empirical test of the extent to which bureaucrats' engagement with citizen input is malleable and whether motivational messages can increase the rate at which bureaucrats engage with information. 


\section{Study setting}

The study took place in fall 2018. It uses a pre-registered randomised field experiment to test the effect of different ways of presenting input derived from citizen participation on access responsiveness $1^{2}$ The participating local authority (LA) has been a strong-hold of the UK's Conservative Party since the Second World War. Its population is ethnically more homogeneous and affluent than the England average. The LA comprised several organisations and a wide range of services, which is typical for large UK local authorities. The LA had undergone a change in leadership in the spring of the same year and - like all other local authorities in England and Wales - was focused on re-designing services to cope with pressures brought on by substantial cuts in central government funding. Over the summer of 2018 the LA engaged in a large-scale effort to collect input from citizens resident in its jurisdiction, to develop a strategy to renew and deliver services over the next decade. The engagement exercise comprised of online surveys, town hall meetings, face-toface interviews and focus group discussions. The authority's outreach team collected the information in conjunction with a marketing agency which had been hired for the purpose. The internal outreach team condensed the information, while the LA's communications team edited the report and compiled messages for internal communication of the results. The final product was

\footnotetext{
${ }^{2}$ The study was pre-registered on AsPredicted a pre-registration platform run by University of Pennsylvania, and ethics approval was obtained from the UCL Research Ethics Committee. Unless otherwise stated, all reported analyses are conducted as pre-registered.
} 
planned to be disseminated via emails to all relevant staff. The purpose was to inform staff about what citizens saw as priorities for the change strategy of the LA and encourage them to work towards delivering on these preferences in their respective areas of work.

I exploited this as an opportunity for a randomised field experiment ${ }^{3}$

A few months before the citizen engagement exercise took place, an internal staff consultation on the current state of affairs and pending changes had concluded. Staff could feed back via an anonymous online survey which consisted of open-ended questions and several multiple choice questions, asking staff to rate different aspects of the local authority as a work place. The local authority shared these results with me. The results revealed that staff was highly cynical about previous and impending organisational change, frustrated with an - allegedly - insular style of working, high demands and low reward offered by their jobs. Barriers for engagement with citizen input, which directly related to new organisational changes, were thus notably high.

The LA had planned to inform all of its staff of the results of the citizen engagement exercise via an organisation-wide email campaign. The date for dissemination was chosen in a manner that council leaders had the chance to view draft summaries first, but the information had not been spread beyond the outreach team and a few members of the executive. This meant that the

\footnotetext{
${ }^{3}$ To recruit a local authority to partner for the trial, emails were sent to all county councils in the UK. The recruitment emails offered them the opportunity to test different approaches to increase staff responsiveness to input from citizen engagement exercises. A total of seven authorities responded to the call ( $24 \%$ of all existing county councils). More information about the recruitment process is available in the online appendix.
} 
information was new to almost all of the bureaucrats employed by the LA and there was scope for them to engage and react to this information.

\section{Implementation}

I compare all interventions against how the LA would have disseminated the information without intervention. The status-quo way of disseminating citizen input in the local authority, in which the experiment takes place, is typical for the UK and most authorities in developed countries. Typically, input is collected and condensed by a central strategy or citizen outreach team. This output is reviewed and signed off by senior bureaucratic and political leadership. It then is sent to relevant bureaucrats via email, which often include links to more detailed information.

With the help of an email management system and bespoke website analytics, I track the behaviour of bureaucrats in response to such emails. All emails contain a summary of the main findings and a link to an intranet page that contains more detail on the findings, broken down by area of work to

highlight relevance (e.g. Children's Social Care, Transport and Planning). The summary highlights key findings from a citizen engagement exercise that the local authority ran in the summer leading up to the trial. Between 3,000 and 4,000 citizens fed in via online surveys, street interviews, town hall debates and meetings co-organised with community groups. The engagement exercise focused on citizen's needs, wishes and ideas for an overhaul of the 
Table 1: Overview of treatment texts

\begin{tabular}{|c|c|c|c|}
\hline Exp. Condition & Subject Line & Key message & Word Count \\
\hline Control & $\begin{array}{l}\text { Results of resident and partner engagement } \\
\text { on [local authority] Vision [future year] }\end{array}$ & $\mathrm{N} / \mathrm{A}$ & 391 \\
\hline Shortened & $\begin{array}{l}\text { Results of resident and partner engagement } \\
\text { Vision [future year] }\end{array}$ & $\mathrm{N} / \mathrm{A}$ & 162 \\
\hline Value & $\begin{array}{l}\text { Views from the people you care about } \\
- \text { [local authority] Vision [future year] }\end{array}$ & $\begin{array}{l}\text { We know you care deeply about the people } \\
\text { you serve through your work every day. We want to } \\
\text { share with you what they value about [local authority] } \\
\text { and what they would like to change. }\end{array}$ & 176 \\
\hline Symbolic & $\begin{array}{l}\text { Thank you for your effort in making } \\
\text { LocalGovName a great place - LocalGovName } \\
\text { Vision YEAR }\end{array}$ & $\begin{array}{l}\text { We would like to thank you for the effort you have } \\
\text { put in to make LocalGovName a great place to live. } \\
\text { We want to share with you what they value about LocalGovName } \\
\text { and what they would like to change. }\end{array}$ & 178 \\
\hline
\end{tabular}

local government's strategy that was to be implemented within the next 10 years. The shortened treatment reduced the word count of the control email by $58 \%$ and simplified its language. All other treatment emails used the same text as the shortened treatment apart from the email subject line and the first sentence, which contained the treatment message (see Table 1 for treatment messages and subject lines; please refer to the online appendix for the full treatment materials).

\section{Dependent variables}

Bureaucrats reading and engaging with information from citizens is the necessary first step to be responsive to them. Schneider (1999) calls this "access responsiveness": the first necessary condition for there to be responsiveness is for citizens concerns to find ears and eyes to be considered.

Relying on self-reports to judge whether bureaucrats take citizen concerns into account is problematic. The divergence between studies that rely on self-report measures and those that rely on observational data suggest that 
when bureaucrats can self-report they might overstate their engagement with input from citizens. Meanwhile observational studies likely under-report on the influence of citizen engagement on policy as they cannot capture individual responses to citizen input. Further, citizen input might find its way into policy design and implementation only gradually. Existing studies have struggled to account for longer-term and slow acting change.

This study addresses some of these methodological shortcomings by using a behavioural measure and an experimental design in which how citizen input is presented to bureaucrats is randomised (see also Table 1 for an overview). The study pre-registered two definitions of the outcome. A scale variable, which is zero when the person did not open the email, one when they opened it, two when they also clicked on the link and three when they spent more than one minute exploring the information on the web-pages. Browsing time is recorded as active browsing for $\geq 1$ minute of cursor activity, scrolling or clicking. This time frame was chosen as it provides for a time window that is (i) long enough to distinguish it from simply opening a tab and navigating away from it and (ii) long enough to navigate to relevant areas and process keywords relevant to one's area of work. While more granular measures of browsing time might have added to the analysis, this was not technically possible when the trial took place.

The scaling is chosen to reflect the assumption that the more steps a bureaucrat completes, the more access responsiveness is given. Since every step requires additional effort, it is also implied that the more steps a bureaucrat 
Table 2: Overview of outcome variables

\begin{tabular}{cl}
\hline Outcome & \multicolumn{1}{c}{ Variable definition } \\
\hline & $\mathrm{Y}_{i}$ in $[0,1,2,3]$, where \\
& $\mathrm{Y}_{i}=0$ when email not opened, \\
Engagement (scale) & $\mathrm{Y}_{i}=1$ when opened, \\
& $\mathrm{Y}_{i}=2$ when opened link clicked \\
& $\mathrm{Y}_{i}=3$ when opened\& \\
& clicked report read \\
\hline & \\
Engagement (binary) & $\mathrm{Y}_{i}$ in $[0,1]$, where \\
& $\mathrm{Y}_{i}=1$ when link clicked, $Y_{i}=0$ \\
\hline
\end{tabular}

completes, the more motivated they are. Using a scale means that distances on the scale are chosen somewhat arbitrary, I also convert the scale to Z-score as a robustness check and for improved interpretability of the analysis. In addition, I also run an ordered logit on the scale variable. I find no difference in results (see online appendix).

In addition, a binary outcome was registered to capture less granular measures of engagement, in the case that the browsing tracking was not deployed correctly. It is set to one when a person clicked on the link contained within the email and to zero when they do not (and thereby cannot get on the webpage containing the citizen input).

The outcomes observed immediately after treatment administration regard access responsiveness: whether bureaucrats actually look at and read the information provided by citizens. Policy design and implementation decisions however take place over several days and weeks. Literature on bureaucratic agencies typically looks at budget allocation as a measure of discretion and independence from political mandate (Ting, 2001). Those that 
investigate the influence of citizens on budgets only find very limited effects (Boulding and Wampler, 2010; Guo and Neshkova, 2012; Cohen et al., 2016).

\section{Hypotheses}

Reducing cognitive load by shortening a message should increase the likelihood of bureaucrats getting to the end of the message and having time to engage beyond this by clicking on the link. To achieve more meaningful engagement, reducing cognitive load is likely insufficient. Compared to the status quo and purely shortened messages, I expect that motivational interventions will significantly increase engagement.

Based on promising results from experiments using symbolic rewards, it is expected that:

Input containing an explicit "thank you" (symbolic reward), will lead to (H1a) greater responsiveness than the control email and (H1b) the shortened and simplified input.

In line with evidence on value-congruence, it is expected that:

Input stressing core values of public service - caring for the opinions of the citizens one serves - will lead to (H2a) greater responsive than the control email and (H2b) the shortened message. 


\section{Participants and randomisation strategy}

Participants of the field experiment were employees of the local authority. A total of 16,013 individuals are registered in the local authority's HR database. The study aimed to target bureaucrats who were - albeit to varying degrees involved in the design and planning of local policies. This meant that 3,498 staff were removed from lists as they worked in unrelated functions - e.g. drivers, cleaning and catering services - and did not use email on a regular basis for their work. Another 4,988 were on short-term, probationary or casual contracts, meaning that they were less likely to be involved in planning activities: either because they had joined only recently (probationary contracts) or were hired to complete already pre-specified tasks (short-term and casual contracts). Such contract-types also had a higher likelihood of having out-of-date email addresses. Therefore, these contacts were removed from the list before randomisation. Four contacts of senior executives were added as they had not been included in the original email list obtained from HR. The final list of employees eligible for participation in the trial thus consisted of 7,532 employees.

The study used blocked (stratified) randomised assignment. The list of 7,532 eligible bureaucrats was randomised into four arms with three stratification variables (blocks) of two levels each: (i) managerial level (manager, no manager), (ii) working in central planning vs. service functions - Lipsky (1983)'s street-level bureaucrats -, and (iii) previous exposure to the citi- 
zen engagement effort (previously exposed, not exposed). The stratification variables were chosen based on the expectation that they would influence treatment effects. Note that no other covariates were used.

It is possible that managers react differently to the intervention compared to people with non-managerial roles. Managers are tasked with designing team strategies to achieve organisational goals; they might therefore face greater pressures to incorporate citizen input than persons who are less involved in planning activities. However, pay grades did not necessarily respond to the degree of responsibility awarded to a person. Following discussions with the authority's HR team, I determined that role descriptors provided a better proxy for managerial responsibilities.

People were classified as having a managerial role if their role descriptors included any of the following words or abbreviations: "manager", "senior", "snr" and - unless it was paired with "assistant" - the words "executive" and "exec". The data set was manually checked for other abbreviations, in order to assure that these captured all markers of managerial level and seniority. A total of 2,194 persons were of managerial rank (29\% of the eligible contacts).

While gender was not recorded in staff data, titles ("Mr", "Mrs", "Ms" and "Miss") were used to infer gender. Only for four cases the title - "Dr" - had no clear gender. For these four cases, trial partner staff identified whether the first name was male or female. Based on their first names, all four cases were classified as female.

People employed in more local and frontline services (street-level bureau- 
crats) might react differently to input from citizens compared to those working in more centralised design and planning functions. They might be more inclined to engage because they are more exposed to citizens in their everyday work and therefore perceive citizen opinion to be more relevant to their work. On the other hand, they might be less inclined to explore such information because they already feel they are informed enough through face-to-face interactions.

Based on their registered location of work, I created a binary indicator for working for central functions or more peripheral and front-line functions. The local authority's strategy, budgeting, planning and other central functions were all located in the county hall at the time of the trial. A total of 1,491 people (20\% of the sample) worked in this central location while 6,073 worked in other functions across the local government area.

Most local governments manage citizen engagement exercises internally. This was also the case with the local authority taking part in the experiment. It is therefore expected that several people will have preliminary information about the citizen engagement exercise. Since they were involved early on, they might be more invested in the cause and thus more likely to respond to the treatment.

To the contrary, they might be less likely to engage with further input, because they feel already informed enough. A total of 54 persons had been exposed to information pertaining to the citizen engagement exercise before the trial $(0.71 \%$ of the sample). 
Table 1 shows the number of observations allocated to each condition by block. I use the R-package randomizr to implement this block randomisation. For the full randomisation code, please refer to the supplementary online materials.

All stratification variables used in this trial were categorical. Chi-squared tests showed that - as expected - their distribution did not differ significantly between experimental conditions (Table 3). Randomisation was blocked by managerial level, central vs. peripheral work location and previous exposure.

Gender was not included in the blocked randomisation but as chi-squared tests illustrate, the difference between the proportion of women and men allocated to each of the treatment arms did not differ from chance (see Table 3).

The type of directorate and whether citizens identified the directorate as a priority area could affect the responsiveness of bureaucrats. As additional balance checks show, randomisation allocated bureaucrats of different directorates, with different citizen priorities attached to them, with equal probabilities into different experimental conditions. Observed responses are thus statistically independent of an affiliation to a directorate and area of priority (see Table 3).

Using MailChimp's 4 recording system for "hard bounces" - failed attempts of delivery after seven trials -, we can assess whether emails were

\footnotetext{
${ }^{4}$ MailChimp is an online mail management service which the local authority was already using for several years before the time of the trial.
} 
Table 3: Balance checks - main treatments

\begin{tabular}{lccccc}
\hline & Control & $\begin{array}{c}\text { Treatment 1 } \\
\text { (Shortened) }\end{array}$ & $\begin{array}{c}\text { Treatment 2 } \\
\text { (Symbolic) }\end{array}$ & $\begin{array}{c}\text { Treatment 3 } \\
\text { (Value) }\end{array}$ & p-value \\
\hline Blocking variables & & & & & \\
Manager & $29.03 \%$ & $28.96 \%$ & $28.96 \%$ & $28.96 \%$ & 1.000 \\
Central & $19.67 \%$ & $19.75 \%$ & $19.74 \%$ & $19.73 \%$ & 0.999 \\
Prev. exposed & $0.74 \%$ & $0.69 \%$ & $0.74 \%$ & $0.69 \%$ & 0.995 \\
Gender & & & & & \\
Male & $30.41 \%$ & $29.01 \%$ & $30.37 \%$ & $30.41 \%$ & 0.731 \\
Female & $69.59 \%$ & $70.99 \%$ & $69.63 \%$ & $69.59 \%$ & \\
Directorates & & & & & \\
Child & & & & & \\
Econo & $29.03 \%$ & $31.02 \%$ & $30.65 \%$ & $28.93 \%$ & 0.617 \\
Finan & $14.38 \%$ & $12.81 \%$ & $14.82 \%$ & $14.44 \%$ & \\
Health & $5.45 \%$ & $5.66 \%$ & $5.35 \%$ & $6.24 \%$ & \\
Highw & $17.77 \%$ & $17.47 \%$ & $17.68 \%$ & $16.87 \%$ & \\
Trans & $5.82 \%$ & $4.71 \%$ & $4.76 \%$ & $4.65 \%$ & \\
Priority Areas & & & & & \\
No priority & $71.02 \%$ & $68.98 \%$ & $69.24 \%$ & $71.07 \%$ & 0.33 \\
Priority & $28.98 \%$ & $31.02 \%$ & $30.76 \%$ & $28.93 \%$ & \\
\hline & & & & \\
\end{tabular}

successfully delivered at the same rate across experimental groups. Emails can bounce due to out-of-date email addresses or technical issues. The email client used for this study captures such bounces. One percent of participants were never-takers because the emails bounced (see Table 44). Because of the low non-compliance rate, I will not estimate the complier average causal effect (CACE).

Percentages for recorded actions by treatment are summarised below in Table 5 and Figure 2. It is immediately evident that more bureaucrats in the two behavioural treatment conditions engaged with citizen input than in the control and the reduced information treatment. While more people who received the shortened email text clicked on the link than in the control, almost none of them spent time on the website. This suggests that low levels 
of engagement are unlikely solely due to information overload. Inferential analyses in the next section unpack this further.

Table 4: Compliance checks

\begin{tabular}{lccccc}
\hline Compliance & \multicolumn{5}{c}{ Treatment } \\
\hline & Control & Shortened & Symbolic & Value & p-value \\
delivered (no) & $99.95 \%$ & $98.09 \%$ & $98.99 \%$ & $97.62 \%$ & 0.001 \\
bounced (yes) & $0.05 \%$ & $1.91 \%$ & $1.01 \%$ & $2.38 \%$ & 0.001 \\
\hline
\end{tabular}

Table 5: Outcomes by experimental group

\begin{tabular}{|c|c|c|c|c|}
\hline & Control & $\begin{array}{l}\text { Treatment } 1 \\
\text { (shortened) }\end{array}$ & $\begin{array}{l}\text { Treatment } 2 \\
\text { (symbolic) }\end{array}$ & $\begin{array}{l}\text { Treatment } 3 \\
\text { (value) }\end{array}$ \\
\hline Not opened & $68.54 \%$ & $84.75 \%$ & $58.52 \%$ & $83.71 \%$ \\
\hline Opened only & $30.20 \%$ & $0.05 \%$ & $24.50 \%$ & $0.00 \%$ \\
\hline Opened + clicked & $1.27 \%$ & $12.23 \%$ & $2.80 \%$ & $1.53 \%$ \\
\hline $\begin{array}{l}\text { Opened }+ \text { clicked }+ \text { opened } \\
\text { web-page browsed info }\end{array}$ & $0.00 \%$ & $2.96 \%$ & $14.18 \%$ & $14.75 \%$ \\
\hline $\mathrm{N}$ & 1,891 & 1,889 & 1,890 & 1,891 \\
\hline
\end{tabular}

\section{Estimation strategy: treatment effects on engagement}

As pre-registered, I use an OLS regression with fixed effects for blocks and heteroscedasticity-consistent ( $\mathrm{HC} 2)$ standard errors to estimate the average treatment effects and repeat the same analysis using a logit model.

$$
Y_{i}=\alpha+\beta_{1} T_{i}+\Gamma A_{i}+\varepsilon_{i}
$$

In this specification, $Y_{i}$ is the response of bureaucrat i. $T_{i}$ is a vector of binary variables that indicate, which treatment the bureaucrat i has been assigned to. The control is always set to zero. $A_{i}$ is a vector of binary blocking 
variables for bureaucrat i based on their area of work, previous involvement in the participation exercise and managerial level. $\varepsilon$ is the error term for bureaucrat i.

\section{Treatment effects on engagement}

In line with the pre-registered analysis plan, I present estimates of treatment effects and significance levels using ordinary least squares (OLS) regressions with fixed effects for blocks. 5

The symbolic and value treatments cause higher levels of engagement (Table 5). Compared to the control, both the value and the symbolic treatment significantly increase engagement compared to the shortened version of the email (see Figure 2). The symbolic treatment leads to greater rates of engagement than the value treatment. It increases engagement by $86 \%$ due to higher open and reading rates - while the value treatment increases engagement by $31 \%$ - a slightly smaller amount due to lower open rates but equally high reading rates - compared to the control. The effect of the shortened message is statistically indistinguishable from that of the control. The effect of the shortened message is statistically indistinguishable from that of the control 6

\footnotetext{
${ }^{5}$ Difference-in-means estimation with randomisation inference introduces less bias Coppock et al., February 1 2018. I present results using this approach in the online appendix and show that estimates are comparable and conclusions are not sensitive to the choice of estimation approach.

${ }^{6}$ Full regression tables, including for pairwise comparisons can be found in the online appendix.
} 
Table 6: Effects on reading, conditional on opening: Lee bounds for effect sizes

\begin{tabular}{ccccc}
\hline & Upper/Lower & Coef & CI low & CI high \\
\hline \multirow{2}{*}{ C vs Short } & Lower & 0.19 & 0.15 & 0.24 \\
& Upper & 0.19 & 0.15 & 0.24 \\
\hline \multirow{2}{*}{ C vs Symbolic } & Lower & 0.13 & 0.05 & 0.22 \\
& Upper & 0.45 & 0.39 & 0.51 \\
\hline \multirow{2}{*}{ C vs Value } & Lower & 0.91 & 0.87 & 0.94 \\
& Upper & 0.91 & 0.87 & 0.94 \\
\hline
\end{tabular}

The first pre-registered outcome uses a binary distinction: whether the bureaucrat opened the email (1) or not (0). It should be noted that simply looking at opening rates would be misleading. If we compare simply whether bureaucrats opened the email and do not distinguish this from more involved actions, it might seem like the value treatment did not perform significantly different to the shortened treatment (see online appendix for a detailed breakdown of this). If we simply broke down actions in this manner, we would see that $15 \%$ of people in the shortened treatment reacted while $16 \%$ did in the value treatment - considerably more, $41 \%$ reacted to the symbolic treatment. However, if we use the scale measure that accounts for the different degrees of effort expanded - from opening, clicking, to actually spending time browsing the information - we see that the value treatment performed significantly better than the shortened message. Using this second pre-registered outcome - a more granular measure - differences become clearer. Fifteen percent of people in the value treatment read the information while only $3 \%$ of those who received the shortened message did. 
Figure 1: Estimated treatment effect of each experimental condition on engagement by type

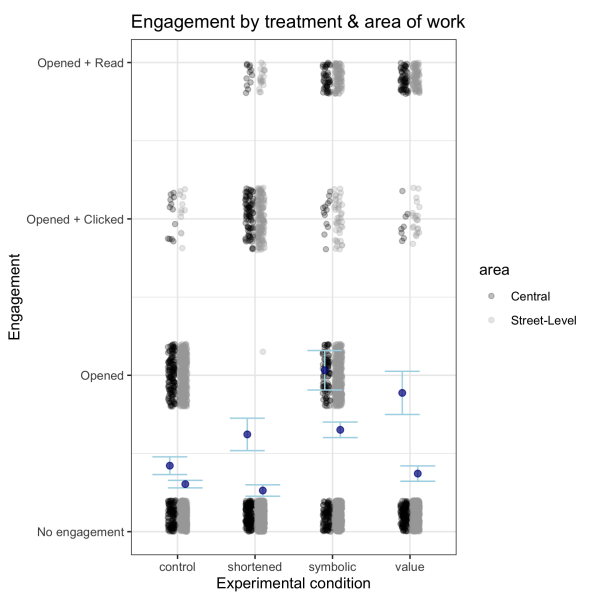

(a) Area of work

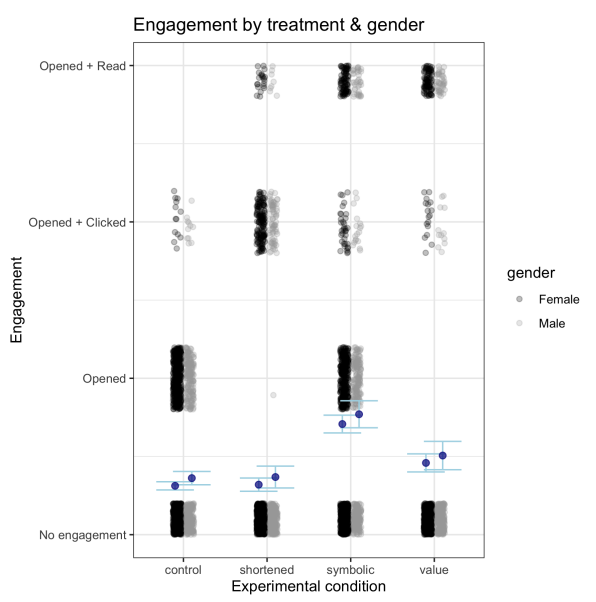

(c) Gender

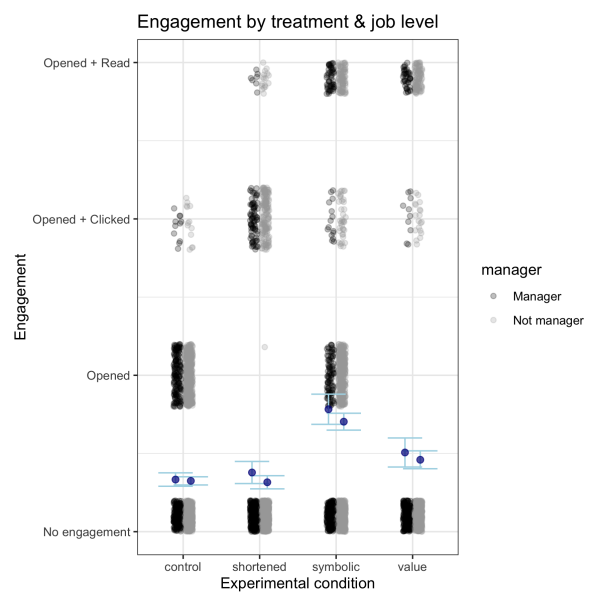

(b) Managerial level

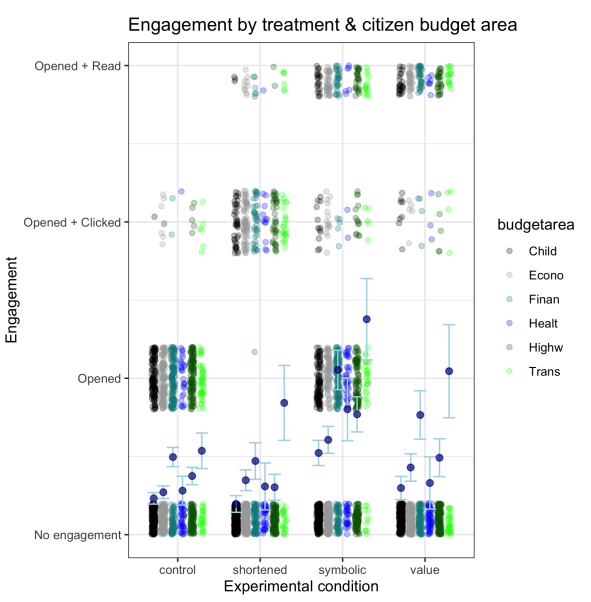

(d) Directorate

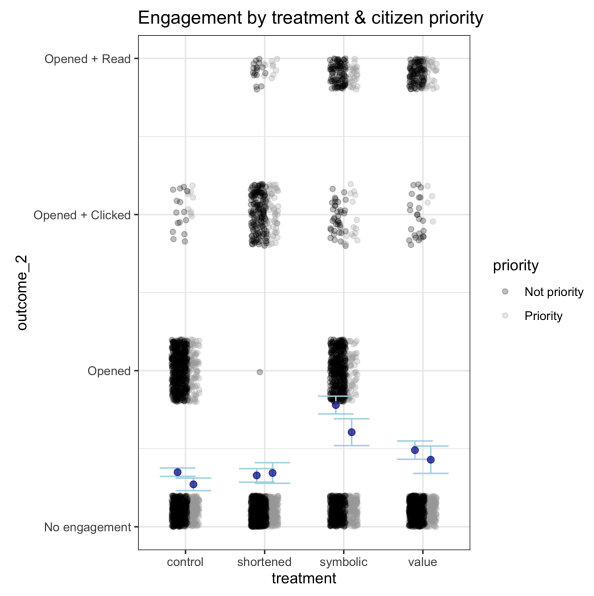

(e) Citizen priority 
Notably, there are considerable differences between opening rates between the symbolic treatment condition and the remaining experimental conditions. I thus also calculate the effect of each treatment condition compared to the control, conditional on opening using the Lee bounds estimation procedure (Lee, 2009). Lee bounds take into account attrition at the preceding stage and trim bounds on treatment effects accordingly. As Table 6 summarises, the effect of the value treatment, conditional on opening, amounts to a $91 \%$ increase in reading rates. The effect of the symbolic treatment ranges between a 13-45\% increase and is thus not distinguishable from the effect of the shortened treatment.

In terms of participant characteristics, working in the central planning unit of the local authority is associated with an increased likelihood that a bureaucrat engages with the input (see Figure??). Those who were involved in the data collection process also engage more. However, the proportion of participants who were exposed to these processes prior to the trial is very small, meaning that estimates are likely to be imprecise and should therefore be interpreted with caution. What areas bureaucrats work in was also related to their likelihood to engage with input. People working in child and school services were the least likely to engage and people working on strategic functions - service planning, digital government and the transformation programme (corporate restructuring, strategy and budget cuts) were the most likely to engage (see Figure $1 \mathrm{~d}$ ). People working in finance and other planning-heavy departments such as highways and environment were 
also more likely to engage with input than people working in departments related to schools and child care.

To gather additional information on information use, I ran a follow-up survey two months after treatment administration. Turnout was low (5\%, $\mathrm{N}=339$ ) and results therefore need to be interpreted with caution. Selfreported use of information broadly reflected the ordering of treatment effects: Among respondents who had received the control email and answered the survey, 20\% reported that they had used the information to inform their work. This compares to $31 \%$ (symbolic) and $38 \%$ (value) for the behavioural treatment groups. More information on the survey and its results is available in the online appendices.

\section{Discussion}

Participatory governance has had a long-standing appeal which found expression in aid conditionality, OECD best practice guides and consultancy tool-kits. Its unique draw lies in the promise of increasing the match between citizen preferences and policy output (Dahl, 1989). Available evidence suggests that participatory governance can have positive effects on citizens' political knowledge and lead to other forms of political participation (Irvin and Stansbury, 2004; John, 2009; Yang and Pandey, 2011; Kroll et al., 2019; Migchelbrink and Van De Walle, 2020). However, it has little to no effects on policy output (Irvin and Stansbury, 2004; Boulding and Wampler, 2010; 
Figure 2: Estimated treatment effect of each experimental condition on engagement

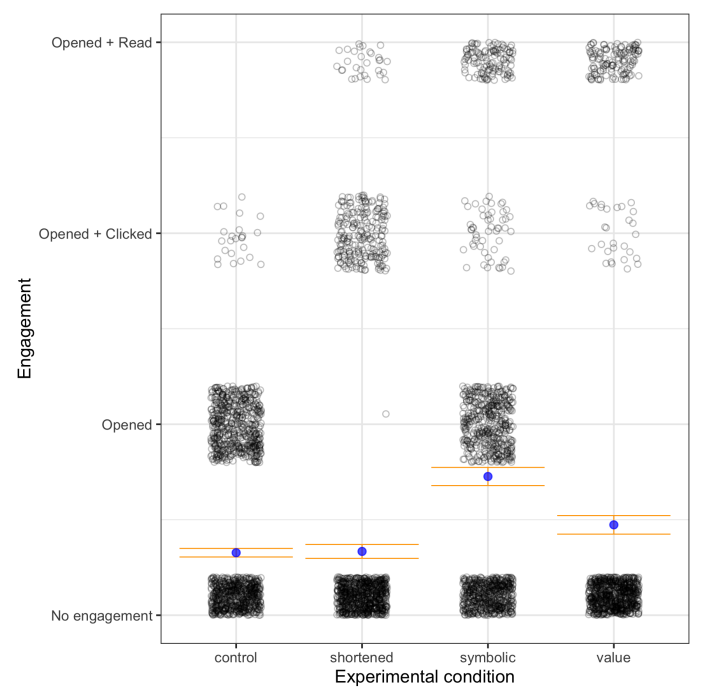

Grey dots indicated individual treatment observations. The darker the area, the more dots are overlaid, meaning that darker areas are indicative of more observations while lighter areas indicate fewer observations. The estimated treatment effects and their confidence intervals are overlaid on the raw data points. Compared to the control, both the value and the symbolic treatment significantly increase engagement compared to the shortened version of the email. The symbolic treatment leads to greater rares of engagement than the value treatment. The effect of the shortened message is statistically indistinguishable from that of the control.

Guo and Neshkova, 2012, Geissel, 2009; Cohen et al., 2016).

What happens in between citizen input and policy output is currently not well understood. Political and institutional factors matter (Font et al., 2018; Boulding and Wampler, 2010) but participatory governance is an arena that affords considerable power to bureaucrats. They are responsible for the commissioning, management and processing of outputs of participatory governance processes such as focus groups, surveys and more recently online versions of townhall debates. Bureaucrats actively engage in policy design 
and prefer it over mere execution (Gains and John, 2010). In their increased recognition or negligence of citizen input bureaucrats can increase or decrease the power of citizen groups over policy. This is especially important in situations where participatory governance initiatives are abused to manufacture consent for autocratic policies or for policies infringing on minority rights.

Bureaucrats generally - but perhaps most prominently exemplified during economic, democratic and health crises - can use citizen input to hold leaders to account. Using "representative statistics" of what the public does and thinks they can ward off against policy choices geared towards rewarding a narrow party base. Representativeness of input can thus become a tool for bureaucrats to shift policy into their preferred direction. What is less talked about but an equally important factor in gating access is apathy amongst bureaucrats. If they do not feel strongly about how citizen input relates to policies, they might regard engagement with it as additional burden to their work.

The results how that bureaucrats' engagement with citizen input can be increased using motivational strategies. Especially the value-based message had a significant and substantial effect - increasing opening, clicking and, most importantly, rates of reading the information. The public administration literature suggests that incentives or administrative controls, personnel selection or motivational strategies can induce bureaucrats to behave in a way that aligns with desired norms. In the case of participatory governance initiatives where discretion is desired to create a more direct link than that 
mediated by political and judicial institutions, motivational strategies appear a particularly attractive solution. This study suggested that they might provide a viable avenue to increase openness to citizen feedback.

Especially when values - an orientation towards serving the public - was emphasised, engagement shifted dramatically compared to when they were approached in the usual way. Using an emphasis on values, $15 \%$ of bureaucrats went and browsed the information on citizen preferences and $14 \%$ did so when their previous efforts were acknowledged with a "thank you". Simplifying information alone did not significantly change engagement.

These findings highlight the influence of bureaucrat behaviour on the potential for participatory governance to succeed. Participatory governance promises to provide citizens with more direct influence on policy, with no or less filtering by politicians. Making bureaucrats aware of what citizens want is thus key to delivering on participatory governance's promises. Yet institutional and political constraints still apply.

For one, as this study clearly showed, the way citizen input is communicated throughout a government organisation can drastically alter its potential to influence bureaucrats. This means that bureaucratic elites, senior management, and those responsible for overseeing participatory governance initiatives can manipulate how credible, attractive and engaging citizen input looks. It could radically alter its potential to affect policy outputs.

That said, central government and agency dependencies matter. This study illustrated how very specific strategies could be used to increase en- 
gagement, however this needs to be seen as a piece to a larger puzzle: how democratic theory, a desire to create more and sustained engagement with policy and policy processes can be created without opening doors to clientelism (see Bertelli and Riccucci (2020) for a more elaborate discussion of the dangers of testing behavioural strategies without proper integration into wider theoretical debates).

Analyses of budget changes following the large participation exercises that the LA under study conducted (see online appendix), suggest that an increase in the number of bureaucrats who engage with this information did not translate into increased investment into those areas marked as citizen priorities - even for those associated with considerable public pressure. Changes are almost entirely explained by the availability of central government grants. This is not surprising given the limited control local governments in the trial location, England, are given. It is however plausible that longer-term changes in the culture of bureaucracies and norms surrounding how policy decision are made can change when engagement with citizen input increases.

Leadership and organisational culture might also influence to what extent the same patterns could be observed in other studies. In this study, bureaucrats were markedly resistant to change. Meanwhile, the senior LA executive who signed off emails to bureaucrats was very well regarded, which might have alleviated some of the negative effects of low staff morale. The observed baseline and rates of post-treatment engagement might differ in other contexts. 
It is possible that if stronger treatments would have been used, larger effects would have been observed. A simple "thank you" is likely the smallest symbolic reward one could imagine. If larger rewards such as employee recognition or award ceremonies were used, the effect might have been larger. Another important avenue for future investigation is the long-term effect of changes to how citizen input is handled. When rhetoric about valuing citizen input and appreciating staff who goes the extra mile is not backed up by actions, it is likely that these interventions will soon lose their effect or even decrease engagement.

Studying what happens in between citizen input and policy output highlights the obstacles to creating effective participatory governance which increases the responsiveness of policy to citizen preferences. While most studies focused on behavioural biases highlight their detrimental effect, this study illustrated how framing effects can lead to positive outcomes. It illustrated that bureaucratic responsiveness to citizen input might not be reflect in budget data, but that bureaucrats can be motivated to engage with feedback at a higher rate. Future studies should therefore investigate how bureaucrats might influence policy design and implementation in response to citizen input, within given budgets. This would further add to the theory of bureaucratic discretion by understanding it not only as a function of budgets but one of human interactions, motivations and subtle changes that can influence how policy is delivered and in turn experienced by citizens.

As the desire for representative yet responsive governance is here to stay, 
researchers will need to gain a better understanding of what role bureaucrats play in shifting the scale towards one or the other. 


\section{References}

Andrews, R. and M. Esteve (2015). Still like ships that pass in the night? the relationship between public administration and management studies. International Public Management Journal: Symposium on the State of Public Management 18(1), 31-60.

Ashraf, N., O. Bandiera, and B. K. Jack (2014). No margin, no mission? A field experiment on incentives for public service delivery. Journal of Public Economics 120, 1-17.

Batory, A. and S. Svensson (2019). The use and abuse of participatory governance by populist governments. Policy and Politics 47(2), 227-244.

Bellé, N. (2015). Performance-related pay and the crowding out of motivation in the public sector: A randomized field experiment. Public Administration Review 75(2), 230-241.

Ben-Ner, A. and L. E. Putterman (1998). Economics, Values, and Organization. Cambridge University Press.

Bertelli, A. and S. E. Feldmann (2007). Strategic appointments. Journal of Public Administration Research and Theory 17(1), 19-38.

Bertelli, A. M. (2012). The Political Economy of Public Sector Governance. New York: Cambridge University Press.

Bertelli, A. M. and N. M. Riccucci (2020). What is behavioral public administration good for? Public administration review.

Boulding, C. and B. Wampler (2010). Voice, Votes, and Resources: Evaluating the Effect of Participatory Democracy on Well-being. World Development 38(1), $125-135$.

Bovaird, T. and E. Löffler (2009). More quality through competitive quality awards? An impact assessment framework. International Review of Administrative Sciences 75(3), 383-401.

Bradler, C. and S. Neckermann (2016). The Magic of the Personal Touch: Field Experimental Evidence on Money and Appreciation as Gifts. Tinbergen Institute. 
Cohen, N., A. Benish, and A. Shamriz-Ilouz (2016). When the Clients Can Choose: Dilemmas of Street-Level Workers in Choice-Based Social Services. Social Service Review 90(4), 620-646.

Dahl, R. A. (1989). Democracy and its critics. New Haven; London: Yale University Press.

Ebdon, C. and A. L. Franklin (2006). Citizen participation in budgeting theory. Public Administration Review 66(3), 437-447.

Esteve, M. and C. Schuster (2019). Motivating public employees. Cambridge elements.

Font, J., G. Smith, C. Galais, and P. Alarcon (2018). Cherry-picking participation: Explaining the fate of proposals from participatory processes. European Journal of Political Research 57(3), 615-636.

Fung, A. (2006). Varieties of participation in complex governance. Public Administration Review 66(SUPPL. 1), 66-75.

Gains, F. and P. John (2010). What do bureaucrats like doing? bureaucratic preferences in response to institutional reform. Public Administration Review 70(3), 455-463.

Gallus, J. (2015). Fostering public good contributions with symbolic awards: A large-scale natural field experiment at wikipedia. Management Science 63(12), 3999-4015.

Geissel, B. (2009). Participatory governance: Hope or danger for democracy? a case study of local agenda 21. 35(4), 401-414.

Grant, A. M., E. M. Campbell, G. Chen, K. Cottone, D. Lapedis, and K. Lee (2007). Impact and the art of motivation maintenance: The effects of contact with beneficiaries on persistence behavior. Organizational Behavior and Human Decision Processes 103(1), 53-67.

Guo, H. D. and M. I. Neshkova (2012). Citizen Input in the Budget Process. The American Review of Public Administration 43(3), 331-346.

Herian, M. N., J. A. Hamm, A. J. Tomkins, and L. M. Pytlik Zillig (2012). Public participation, procedural Fairness, and evaluations of local governance: The moderating role of uncertainty. Journal of Public Administration Research and Theory 22(4), 815-840. 
Irvin, R. A. and J. Stansbury (2004). Citizen Participation in Decision Making: Is It Worth the Effort? Public Administration Review 64(1), 55-65.

John, P. (2009). Can citizen governance redress the representative bias of political participation? Public Administration Review 69(3), 494-503.

Kroll, A., M. I. Neshkova, and S. K. Pandey (2019). Spillover effects from customer to citizen orientation: How performance management reforms can foster public participation. Administration Society 51(8), 1227-1253.

Lee, D. S. (2009, 07). Training, Wages, and Sample Selection: Estimating Sharp Bounds on Treatment Effects. The Review of Economic Studies 76(3), 10711102.

Lipsky, M. (1983). Street-Level Bureaucracy The Dilemmas of the Individual in Public Service. Publications of Russell Sage Foundation Street-level bureaucracy. New York: Russell Sage Foundation.

Lowndes, V., L. Pratchett, and G. Stoker (2001). Trends in public participation: Part 2 - Citizens' perspectives. Public Administration 79(2), 445-455.

Maricuţoiu, L. P., F. A. Sava, and O. Butta (2016). The effectiveness of controlled interventions on employees' burnout: A meta-analysis. Journal of Occupational and Organizational Psychology 89(1), 1-27.

Meier, K. J. and L. J. O'Toole (2006). Political control versus bureaucratic values: Reframing the debate. Public Administration Review 66(2), 177-192.

Michels, A. (2011). Innovations in democratic governance: how does citizen participation contribute to a better democracy? International Review of Administrative Sciences 77(2), 275-293.

Migchelbrink, K. and S. Van De Walle (2020). When will public officials listen? a vignette experiment on the effects of input legitimacy on public officials' willingness to use public participation. Public Administration Review 80(2), 271-280.

Miller, G. J. and A. B. Whitford (2016). Above politics : bureaucratic discretion and credible commitment. Political economy of institutions and decisions.

Moreno, R. and B. Park (2010). Cognitive load theory: Historical development and relation to other theories. Cognitive Load Theory, 7-28.

OECD (2009). Focus on Citizens - Public engagement for Better Policy and Services. 
Page, E. C. (2012). Policy Without Politicians: Bureaucratic Influence in Comparative Perspective. Oxford: Oxford University Press.

Panagopoulos, C. (2011). Thank you for voting: Gratitude expression and voter mobilization. Journal of Politics 73(3), 707-717.

Peixoto, T., F. M. Sjoberg, and J. Mellon (2020). A get-out-the-vote experiment on the world's largest participatory budgeting vote in brazil. British Journal of Political Science 50(1), 381-389.

Perry, J. L. (2015). Public Service Motivation Research: Achievements, Challenges, and Future Directions. Public Administration Review 75 (5), 692-699.

Prendergast, C. (2007). The motivation and bias of bureaucrats. American Economic Review 97(1), 180-196.

Ritz, A. (2015). Public service motivation and politics: Behavioural consequences among local councillors in Switzerland. Public Administration 93(4), 1121-1137.

Schneider, H. (1999). Participatory governance for poverty reduction. Journal of International Development 11(4), 521-534.

Speer, J. (2012). Participatory Governance Reform: A Good Strategy for Increasing Government Responsiveness and Improving Public Services? World Development 40(12), 2379-2398.

Ting, M. M. (2001). The "Power of the purse" and its implications for bureaucratic policy-making. Public Choice 106(3-4), 243-274.

Trump Headquarters, T. G. O. P. (2018). Offical State of the Union Survey.

Tummers, L. and V. Bekkers (2014). Policy Implementation, Street-level Bureaucracy, and the Importance of Discretion. Public Management Review 16(4), $527-547$.

Verba, S., K. L. Schlozman, and H. E. Brady (1995). Voice and equality : civic voluntarism in American politics. Cambridge, Mass. ; London: Harvard University Press.

Yang, K. and K. Callahan (2007). Citizen involvement efforts and bureaucratic responsiveness: Participatory values, stakeholder pressures, and administrative practicality. Public Administration Review 67(2), 249-264. 
Yang, K. and S. K. Pandey (2011). Further Dissecting the Black Box of Citizen Participation: When Does Citizen Involvement Lead to Good Outcomes? Public Administration 71(6), 880-892. 


\title{
Online Appendix
}

Motivation-based messages increase elite engagement with citizen feedback

\author{
Annabelle S. Wittels
}

May 30, 2021

\section{Contents}

1 Additional details on the trial context 2

1.1 Recruitment . . . . . . . . . . . . . . . . . . . . . . 2

1.2 Implementation - additional details $\ldots \ldots \ldots \ldots . \ldots \ldots$

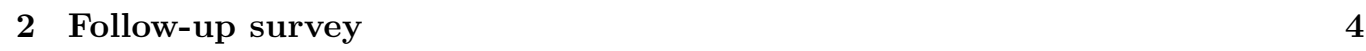

2.1 Results - Follow-up survey $\ldots \ldots \ldots$. . . . . . . . . . . . . . . 4

\begin{tabular}{|lll}
3 & Additional details on data and estimation & 6
\end{tabular}

3.1 Distribution of outcome variable . . . . . . . . . . . . . . . 6

3.2 Distribution of blocking variables $\ldots \ldots \ldots \ldots \ldots$

$3.3 \quad$ Results: Regression tables . . . . . . . . . . . . . . . . . . . . . . . 10

3.4 Additional analyses: Engagement defined as clicking on link - simplified

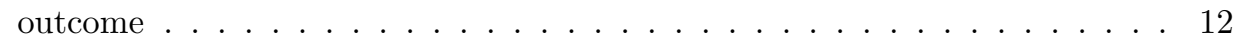

$3.5 \quad$ Additional analyses: Pairwise comparisons between treatment conditions. . 14

3.6 Main analyses: Additional robustness checks $\ldots \ldots \ldots 18$

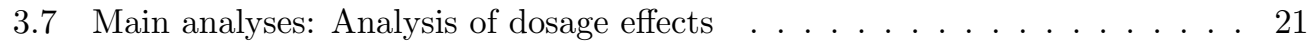

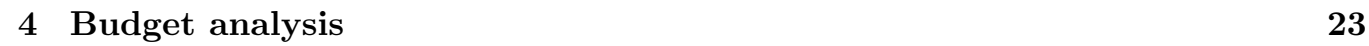

5 Intervention materials $\quad 28$

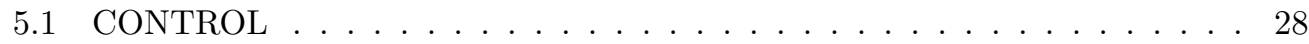

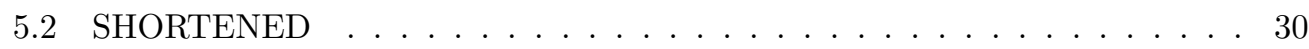

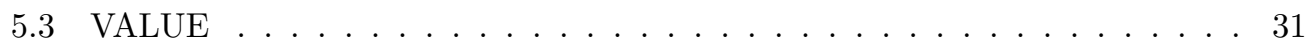

5.4 SYMBOLIC REWARDS $\ldots \ldots \ldots \ldots \ldots \ldots$. . . . . . . . . . . . . . . . 32

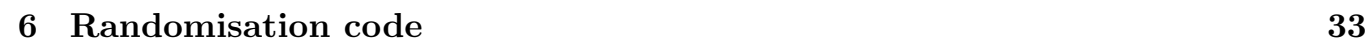




\section{Additional details on the trial context}

\subsection{Recruitment}

County councils in the UK are responsible for the provision of a wide range of government services including education, transport, fire and public safety, social care (welfare), libraries, waste management and the regulation of local trading standards. County councils employ a large number of staff, with a central planning unit. Front-line services and heads of frontline services report into this central structure. Thus, using county councils

- local authorities - as case studies allows me to test hypotheses both on more commonly studied street-level bureaucrats (Lipsky, 1983) and less studied senior bureaucrats with planning roles.

Recruitment emails were sent to all county councils in the UK. The recruitment emails offered them the opportunity to test different approaches to increase staff responsiveness to input from citizen engagement exercises.

A total of seven authorities responded to the call ( $24 \%$ of all existing county councils). The authorities were all located in England but of varying size, political leadership, population characteristics and legal statue. I evaluated the suitability based on available sample size and time frames. With one local authority, only a pilot trial was possible due to the limited amount of bureaucrats for whom the citizen input would have been actionable. Four other county councils faced budget and time constraints that made participation within the period of the research grant unfeasible.

I then assessed whether the local authority had any on-going citizen engagement exercises that were suitable for the study. Ideally, the engagement exercise should produce results that are relevant for a maximum number of staff and should be high-profile, so that it is less likely that the treatment would be crowded out by other staff communication. Based on the characteristics, one large authority in the South of England was selected. 


\subsection{Implementation - additional details}

The interventions were all distributed via emails using an email distribution client regularly used for internal communications across the authority: MailChimp. The sender for all of these emails was an executive director. All emails were sent on the same day, at the same time. Open and click activity was recorded through HTML and java script code embedded in the emails, and automatically registered by the email client. Website activity was recorded through website analytics, which were already in place for all intranet pages of the local authority. A special parameter was added to the URLs of relevant intranet pages, which meant that the unique ID of each of the emails was recorded. This made it possible to track whether an individual bureaucrat (i) opened the email, (ii) clicked on the link and (iii) to what extent they browsed the relevant intranet pages.

Firewall and email settings can block the java script code included in the experimental emails, meaning that opens and clicks are not tracked. However, the unique ID embedded in the URL can still be registered by the website analytics of the intranet pages. As the intranet pages cannot be accessed without this URL, one can safely assume that someone who was registered visiting the intranet page must have also opened the email and clicked on the link. This means that for observations, for which opens and clicks failed to be recorded but activity on the intranet pages was recorded, binary variables for opens and clicks can be set to one. This was the case for 292 participants (3.87\% of the sample).

Emails can bounce due to out-of-date email addresses or technical issues. The email

client used for this study captures such bounces. A total of one percent of participants were never-takers because the emails bounced. 


\section{Follow-up survey}

A follow-up survey was conducted two months after exposure to the treatment. The purpose of this survey was to (i) test whether bureaucrats recalled the information correctly, (ii) whether they used the information for policy design or implementation and (iii) to identify facilitating factors and barriers to using citizen input.

In the first week of December, two months after the treatment was administered, all participants received an email that contained a link to a short survey and their anonymised ID, which was the same as in the experiment. Survey participation was incentivised with a lottery. Respondents could win $£ 200$ credit that they could give to a charity of their choice. Before entering the survey they were asked for their ID. The initial survey invitation was sent on a Tuesday, a reminder was sent on the Friday of the same week and another reminder on the Wednesday of the following week. Bureaucrats were given two weeks to respond.

\subsection{Results - Follow-up survey}

A total of 339 bureaucrats completed the survey. Of them, 334 provided a valid ID. Data for these 334 is analysed. Based on feedback from the local government's HR team, the survey was largely representative in terms of the departmental affiliation and tenure of the

respondents. However, turnout was surprisingly low. Despite incentivisation only $5 \%$ of those contacted completed the survey. These low response rates might be linked to survey fatigue as a large scale staff consultation took place about six to nine months before this survey was launched. Owing to the low response rate and resulting small sample size, the results of this survey are not presented in the main part of the paper. All results should be interpreted with a view towards the likelihood of selection bias present in the type of person who responds to the survey and the fact that the sample size is too small to perform reliable instrumental variable analyses to assess a link between treatment exposure and 
Table 1: Logit model of the effect of treatment assignment on survey completion

\begin{tabular}{ll}
\hline \hline \multicolumn{2}{c}{ Completion of survey (binary) } \\
& $\mathrm{b} / \mathrm{se}$ \\
\hline Shortened & 0.012 \\
& $(-0.155)$ \\
Symbolic & -0.142 \\
& $(-0.161)$ \\
Value & -0.048 \\
& $(-0.157)$ \\
\hline Constant & $-3.032^{* *}$ \\
& $(-0.11)$ \\
\hline Observations & 7,563 \\
\hline \hline$+\mathrm{p}<0.1,{ }^{*} \mathrm{p}<0.05,{ }^{* *} \mathrm{p}<0.01$ &
\end{tabular}

answers to the survey.

Once merged with data from the experiment, I found that only 134 of them had opened the initial emails within the experimental period (it is possible that they went back through their unopened emails at the time of the survey). Treatment changed the propensity of opening emails. However, the proportion of respondents who had opened the emails and responded to the survey did not differ between treatment groups. This means that people who had originally received the control email and opened it were over-represented in the survey compared to other groups. Since the invitation email to the survey was the same for all treatment groups, it is plausible that we observe self-selection into the survey based on personal preference, which - due to randomisation - is equally distributed across treatment groups. Survey response thus is likely independent of whether the initial treatment email was opened. A logit regression that shows no significant association between treatment assignment and completion provides support for this hypothesis (Table 1).

Only $20 \%$ of respondents who had received the control email reported that they had used the information. This compares to $31 \%$ (symbolic) and $38 \%$ (value) for the behavioural treatment groups. For those who had opened the email during the experimental period, $20 \%$ in the control reported using it, $20 \%$ In the shortened email, $30 \%$ in the value 
and $30 \%$ in the symbolic treatment groups. Despite there being no association between treatment assignment and completion of the survey, we still see effects of (self-reported) use. Bureaucrats did not only engage at a higher rate with citizen input, but also used it at a higher rate. This suggests that using behaviourally informed communication tactics could increase the influence that citizens have over bureaucrat decision-making.

Respondents who had received the value treatment email and opened it also showed lower ratings of feeling overburdened $(\mathrm{p}<0.01)$. Those who had received the thank-you email and opened it, reported that they felt more capable of implementing changes that citizens wanted $(\mathrm{p}<0.01)$. There were no other significant differences in scores between conditions.

\section{Additional details on data and estimation}

\subsection{Distribution of outcome variable}

The plot below shows the frequency of each behavioural action. The table further breaks down frequencies by treatment condition.

Table 2: Counts of persons engaging in outcome behaviours by treatment condition

\begin{tabular}{lccccc}
\hline & No engagement & Opened only & Opened + Clicked & Opened + Clicked +Read & Total \\
\hline Control & 1,296 & 571 & 24 & 0 & $\mathbf{5 , 5 8 6}$ \\
Shortened & 1,601 & 1 & 231 & 56 & $\mathbf{1 , 0 3 5}$ \\
Symbolic & 1,106 & 463 & 53 & 268 & $\mathbf{3 3 7}$ \\
Value & 1,583 & 0 & 29 & 279 & $\mathbf{6 0 3}$ \\
\hline Total & 5,586 & 1,035 & 337 & 603 & $\mathbf{7 , 5 6 1}$ \\
\hline
\end{tabular}


Figure 1: Distribution of behavioural actions

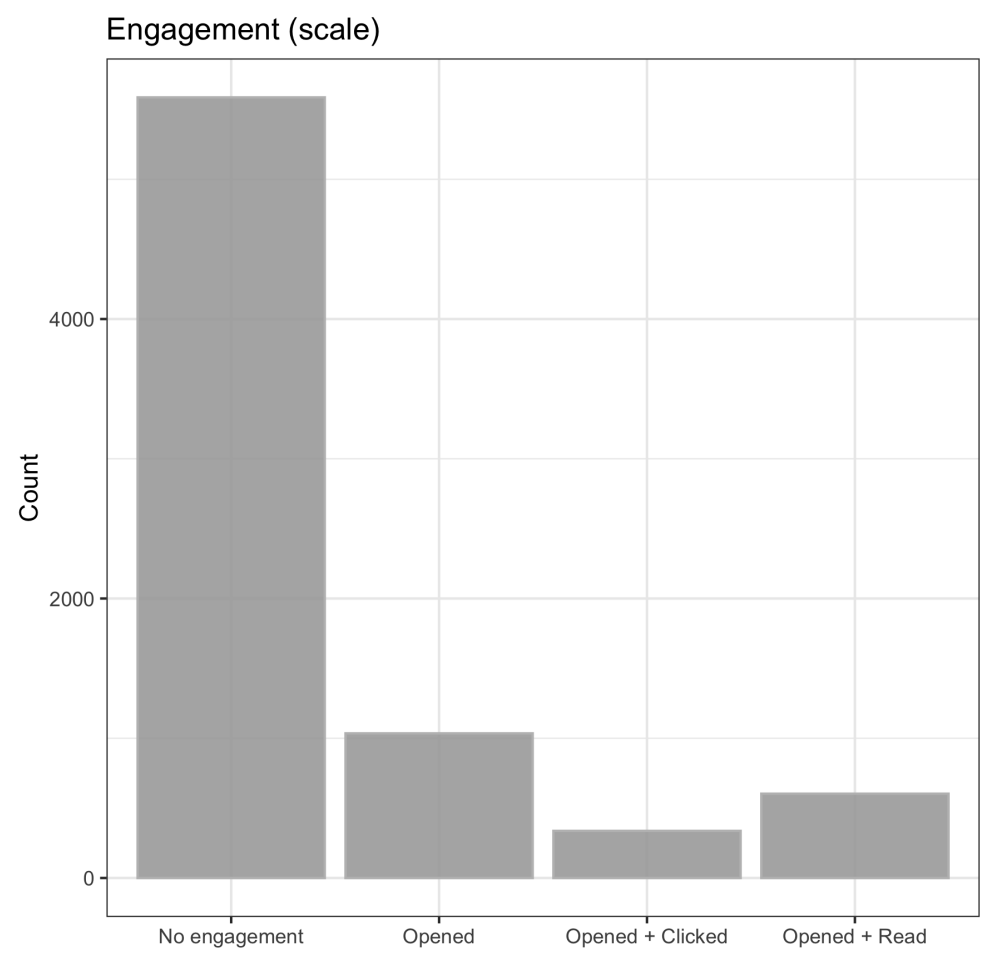




\subsection{Distribution of blocking variables}

The tables below detail the distribution of blocking variables within the sample (Table 3), across treatment groups (Table 4) and outcomes (Table 5).

Table 3: Outcome by blocking variable

\begin{tabular}{cccc}
\hline Blocking variable & Value & $\mathbf{N}$ & Pct. \\
\hline \multirow{2}{*}{ Manager } & 0 & 5,367 & 70.99 \\
& 1 & 2,193 & 29.01 \\
\hline \multirow{2}{*}{ Central } & 0 & 6,070 & 80.29 \\
& 1 & 1,490 & 19.71 \\
\hline \multirow{2}{*}{ Prev. exposed } & 0 & 7,506 & 99.29 \\
& 1 & 54 & 0.71 \\
\hline Total & & 7,560 & 100 \\
\hline
\end{tabular}

Table 4: Blocks by treatment status

\begin{tabular}{lllllll}
\hline Blocking variable & Unit & Control & shortened & symbolic & value & Total \\
\hline \multirow{2}{*}{ Not manager } & $\mathrm{N}$ & 1,342 & 1,342 & 1,341 & 1,342 & 5,367 \\
& Pct. & 70.97 & 71.04 & 70.99 & 70.97 & 70.99 \\
\hline \multirow{2}{*}{ Manager } & $\mathrm{N}$ & 549 & 547 & 548 & 549 & 2,193 \\
& Pct. & 29.03 & 28.96 & 29.01 & 29.03 & 29.01 \\
\hline \multirow{2}{*}{ Central } & $\mathrm{N}$ & 372 & 373 & 372 & 373 & 1,490 \\
& Pct. & 19.67 & 19.75 & 19.69 & 19.73 & 19.71 \\
\hline \multirow{2}{*}{ Peripheral } & $\mathrm{N}$ & 1,519 & 1,516 & 1,517 & 1,518 & 6,070 \\
& Pct. & 80.33 & 80.25 & 80.31 & 80.27 & 80.29 \\
\hline \multirow{2}{*}{ Not prev. exposed } & $\mathrm{N}$ & 1,877 & 1,876 & 1,875 & 1,878 & 7,506 \\
& Pct. & 99.26 & 99.31 & 99.26 & 99.31 & 99.29 \\
\hline \multirow{2}{*}{ Prev. exposed } & $\mathrm{N}$ & 14 & 13 & 14 & 13 & 54 \\
& Pct. & 0.74 & 0.69 & 0.74 & 0.6 & 0.71 \\
\hline
\end{tabular}


Table 5: Outcomes by block

\begin{tabular}{cccccc}
\hline Blocking variable & Value & Not opened & Opened only & Opened + clicked & Opened + clicked + browsed \\
\hline \multirow{2}{*}{ Manager } & 0 & 71.07 & 74.85 & 66.17 & 66.33 \\
& 1 & 28.93 & 25.15 & 33.83 & 33.67 \\
\hline \multirow{2}{*}{ Central } & 0 & 16.86 & 20.50 & 34.42 & 36.48 \\
& 1 & 16.86 & 20.50 & 34.42 & 36.48 \\
\hline \multirow{2}{*}{ Prev. exposed } & 0 & 99.50 & 98.94 & 99.11 & 98.01 \\
\hline Total & 1 & 0.50 & 1.06 & 0.89 & 603 \\
\hline
\end{tabular}




\subsection{Results: Regression tables}

Below are the regression results for figures reported in the main paper in texts and represented graphically.

Table 6: OLS regression with fixed effects for blocks

\begin{tabular}{|c|c|}
\hline & $\begin{array}{c}(1) \\
\text { Engagement as binary outcome } \\
\mathrm{b} / \mathrm{se}\end{array}$ \\
\hline shortened & $\begin{array}{c}0.139^{* *} \\
(0.009)\end{array}$ \\
\hline symbolic & $\begin{array}{c}0.157^{* *} \\
(0.009)\end{array}$ \\
\hline value & $\begin{array}{c}0.150^{* *} \\
(0.009)\end{array}$ \\
\hline Manager & $\begin{array}{c}0.023^{* *} \\
(0.008)\end{array}$ \\
\hline Central & $\begin{array}{c}0.122^{* *} \\
(0.011)\end{array}$ \\
\hline exposed=1 & $\begin{array}{l}0.100+ \\
(0.058)\end{array}$ \\
\hline Constant & $\begin{array}{c}-0.019^{* *} \\
(0.004)\end{array}$ \\
\hline$R^{2}$ & 0.06 \\
\hline Observations & 7561 \\
\hline
\end{tabular}


Table 7: OLS regression with fixed effects for blocks:

\begin{tabular}{lc}
\hline \hline & $(1)$ \\
& $\begin{array}{c}\text { Engagment (scale) } \\
\mathrm{b} / \mathrm{se}\end{array}$ \\
\hline shortened & 0.007 \\
& $(0.022)$ \\
symbolic & $0.399^{* *}$ \\
& $(0.027)$ \\
value & $0.146^{* *}$ \\
& $(0.027)$ \\
Manager & 0.033 \\
& $(0.023)$ \\
Central & $0.334^{* *}$ \\
& $(0.030)$ \\
exposed=1 & $0.363^{*}$ \\
& $(0.162)$ \\
Constant & $0.249^{* *}$ \\
& $(0.014)$ \\
\hline$R^{2}$ & 0.06 \\
Observations & 7561 \\
\hline \hline+ pi $0.1,{ }^{*} p_{i} 0.05,{ }^{* *}$ & $p_{i} 0.01$
\end{tabular}




\subsection{Additional analyses: Engagement defined as click- ing on link - simplified outcome}

When the trial was pre-registered, it was uncertain whether more granular actions than having clicked on the link contained in the emails was possible. In the end, this was the case and the main paper reports on the results using the more granular measure, which distinguishes between opens only, clicks only and clicks and active reading time. For completeness, I also report on the results of the pre-registered simplified measure, which only distinguishes between clicking or not clicking. Looking at engagement as a binary variable - whether bureaucrats clicked on the link to learn more or not -, the shortened, value and symbolic treatments all increased engagement compared to the control. These differences are significant at $\mathrm{p}<0.001$. Differences between treatments are however not significant. 
Figure 2: Engagement, defined binary: no engagement vs meaningful engagement; by experimental condition

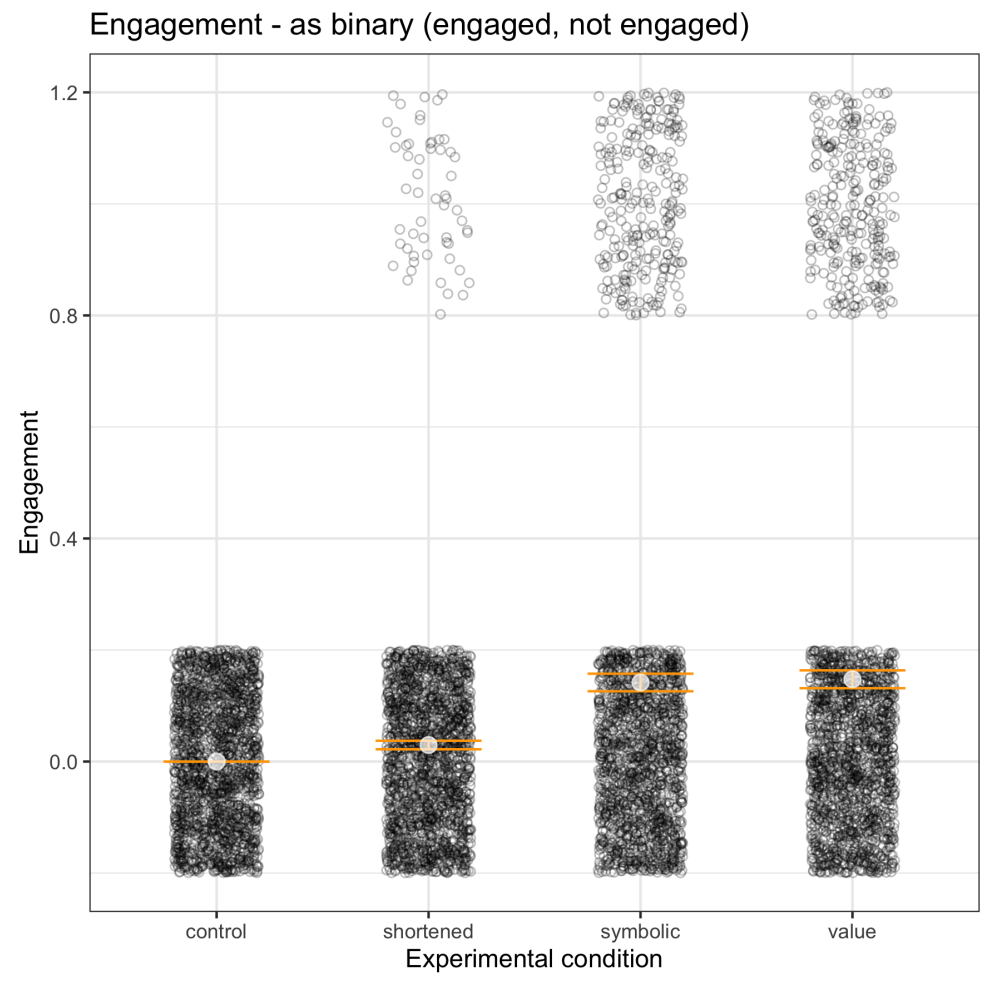

Grey dots indicated individual treatment observations. The darker the area, the more dots are overlaid, meaning that darker areas are indicative of more observations while lighter areas indicate fewer observations. The estimated treatment effects and their confidence intervals are overlaid on the raw data points. 


\subsection{Additional analyses: Pairwise comparisons between treatment conditions}

The section below presents all regression results for pairwise comparisons between experimental conditions.

Table 8: Pairwise comparison: Compared against 'shortened' treatment

\begin{tabular}{lc}
\hline \hline & $(1)$ \\
& Compared against 'shortened' treatment \\
& $\mathrm{b} / \mathrm{se}$ \\
\hline control & $-0.139^{* *}$ \\
& $(0.009)$ \\
symbolic & 0.018 \\
& $(0.012)$ \\
value & 0.011 \\
& $(0.012)$ \\
Manager & $0.023^{*}$ \\
& $(0.008)$ \\
Central & $0.122^{* *}$ \\
& $(0.011)$ \\
exposed $=1$ & 0.100 \\
& $(0.058)$ \\
Constant & $0.121^{* *}$ \\
& $(0.008)$ \\
\hline$R^{2}$ & 0.06 \\
Observations & 7561 \\
\hline \hline+ pi.033, ${ }^{*}$ pi.017, ${ }^{* *}$ pi.003
\end{tabular}


Table 9: Pairwise comparison: Compared against 'value' treatment

\begin{tabular}{lc}
\hline \hline & $(1)$ \\
& Compared against 'value' treatment \\
& $\mathrm{b} / \mathrm{se}$ \\
\hline control & $-0.150^{* *}$ \\
& $(0.009)$ \\
shortened & -0.011 \\
& $(0.012)$ \\
symbolic & 0.007 \\
& $(0.012)$ \\
Manager & $0.023+$ \\
& $(0.008)$ \\
Central & $0.122^{* *}$ \\
& $(0.011)$ \\
exposed $=1$ & 0.100 \\
& $(0.058)$ \\
Constant & $0.132^{* *}$ \\
& $(0.009)$ \\
\hline$R^{2}$ & 0.06 \\
Observations & 7561 \\
\hline \hline
\end{tabular}

Table 10: Pairwise comparison: Compared against 'symbolic' treatment )

\begin{tabular}{lc}
\hline \hline & $(1)$ \\
& Compared against 'symbolic' treatment \\
& $\mathrm{b} / \mathrm{se}$ \\
\hline control & $-0.157^{* *}$ \\
& $(0.009)$ \\
shortened & -0.018 \\
& $(0.012)$ \\
value & -0.007 \\
& $(0.012)$ \\
Manager & $0.023^{*}$ \\
& $(0.008)$ \\
Central & $0.122^{* *}$ \\
& $(0.011)$ \\
exposed $=1$ & 0.100 \\
& $(0.058)$ \\
Constant & $0.138^{* *}$ \\
& $(0.009)$ \\
\hline$R^{2}$ & 0.06 \\
Observations & 7561 \\
\hline \hline+ pi.017, ${ }^{*}$ pi. $008,{ }^{* *}$ pi.003 &
\end{tabular}


Table 11: Pairwise comparison: engagment (scale)

\begin{tabular}{lc}
\hline \hline & $(1)$ \\
& Compared against 'shortened' treatment \\
& $\mathrm{b} / \mathrm{se}$ \\
\hline control & -0.007 \\
& $(0.022)$ \\
symbolic & $0.392^{* *}$ \\
& $(0.030)$ \\
value & $0.139^{* *}$ \\
& $(0.030)$ \\
Manager & 0.033 \\
& $(0.023)$ \\
Central & $0.334^{* *}$ \\
& $(0.030)$ \\
exposed $=1$ & $0.363+$ \\
& $(0.162)$ \\
Constant & $0.256^{* *}$ \\
& $(0.019)$ \\
\hline$R^{2}$ & 0.06 \\
Observations & 7561 \\
\hline \hline
\end{tabular}

+ pi.033, * pi.017, ** pi.003

Table 12: Pairwise comparison: engagment (scale)

\begin{tabular}{lc}
\hline \hline & $(1)$ \\
& Compared against 'value' treatment \\
& $\mathrm{b} / \mathrm{se}$ \\
\hline control & $-0.146^{* *}$ \\
& $(0.027)$ \\
shortened & $-0.139^{* *}$ \\
& $(0.030)$ \\
symbolic & $0.253^{* *}$ \\
& $(0.034)$ \\
Manager & 0.033 \\
& $(0.023)$ \\
Central & $0.334^{* *}$ \\
& $(0.030)$ \\
exposed=1 & 0.363 \\
& $(0.162)$ \\
Constant & $0.395^{* *}$ \\
& $(0.025)$ \\
\hline$R^{2}$ & 0.06 \\
Observations & 7561 \\
\hline \hline+ pi.011, ${ }^{*}$ pi.006, ${ }^{* *}$ pi.001 & \\
\end{tabular}


Table 13: Pairwise comparison: engagment (scale)

\begin{tabular}{lc}
\hline \hline & $(1)$ \\
& Compared against 'symbolic' treatment \\
& $\mathrm{b} / \mathrm{se}$ \\
\hline control & $-0.399^{* *}$ \\
& $(0.027)$ \\
shortened & $-0.392^{* *}$ \\
& $(0.030)$ \\
value & $-0.253^{* *}$ \\
& $(0.034)$ \\
Manager & 0.033 \\
& $(0.023)$ \\
Central & $0.334^{* *}$ \\
& $(0.030)$ \\
exposed $=1$ & 0.363 \\
& $(0.162)$ \\
Constant & $0.648^{* *}$ \\
& $(0.025)$ \\
\hline$R^{2}$ & 0.06 \\
Observations & 7561 \\
\hline \hline+ pi.017, ${ }^{*}$ pi.008, ${ }^{* *}$ pi.003 &
\end{tabular}




\subsection{Main analyses: Additional robustness checks}

For engagement defined as a scale variable, I re-run all analyses with standardised scores. Conclusions do not differ from the main analyses.

Table 14: Robustness check: OLS regression with fixed effects for blocks engagement (scale) as z-score

\begin{tabular}{lc}
\hline \hline & $(1)$ \\
& $\begin{array}{c}\text { Engagement (scale) } \\
\mathrm{b} / \mathrm{se}\end{array}$ \\
\hline control & -0.008 \\
& $(0.025)$ \\
symbolic & $0.451^{* *}$ \\
& $(0.044)$ \\
value & $0.159^{* *}$ \\
& $(0.035)$ \\
manager $=1$ & 0.028 \\
& $(0.027)$ \\
area $=1$ & $0.376^{* *}$ \\
& $(0.036)$ \\
exposed $=1$ & $0.337+$ \\
& $(0.187)$ \\
Constant & $-0.192^{* *}$ \\
& $(0.022)$ \\
\hline Observations & 6,616 \\
\hline \hline$+\mathrm{p}<0.1,{ }^{*} \mathrm{p}<0.05, * *$ & $\mathrm{p}<0.01$
\end{tabular}

I also repeat the analyses using an ordered logit model. As the table below shows, again, conclusions do not change from those from the primary model (OLS with fixed effects for blocks) reported in the main part of the paper. 
Table 15: Ordered logistic regression: Effect of treatment on engagement, expressed in odds ratios

\begin{tabular}{|c|c|}
\hline & $\begin{array}{c}(1) \\
\text { Engagement (scale) } \\
\mathrm{b} / \mathrm{se}\end{array}$ \\
\hline shortened & $\begin{array}{c}-0.682^{* *} \\
(0.080)\end{array}$ \\
\hline symbolic & $\begin{array}{c}0.596^{* *} \\
(0.060)\end{array}$ \\
\hline value & $\begin{array}{c}-0.518^{* *} \\
(0.084)\end{array}$ \\
\hline manager $=1$ & $\begin{array}{c}0.029 \\
(0.059)\end{array}$ \\
\hline area $=1$ & $\begin{array}{c}0.725^{* *} \\
(0.064)\end{array}$ \\
\hline exposed $=1$ & $\begin{array}{c}0.699^{*} \\
(0.288)\end{array}$ \\
\hline cut1 & \\
\hline Constant & $\begin{array}{c}1.143^{* *} \\
(0.050)\end{array}$ \\
\hline cut2 & \\
\hline Constant & $\begin{array}{c}2.099 * * \\
(0.044)\end{array}$ \\
\hline cut3 & \\
\hline Constant & $\begin{array}{c}2.600^{* *} * \\
(0.050)\end{array}$ \\
\hline Observations & 7,561 \\
\hline
\end{tabular}


Table 16: Ordered logistic regression: Pairwise comparisons; in odds ratios

\begin{tabular}{|c|c|c|c|}
\hline & $\begin{array}{c}(1) \\
\text { Engagement (scale) } \\
\mathrm{b} / \mathrm{se}\end{array}$ & $\begin{array}{c}(2) \\
\text { pairwise2_3 } \\
\text { b/se }\end{array}$ & $\begin{array}{c}\text { (3) } \\
\text { pairwise2_4 } \\
\text { b/se }\end{array}$ \\
\hline control & $\begin{array}{c}0.682^{* *} \\
(0.080)\end{array}$ & $\begin{array}{c}-0.596^{* *} \\
(0.060)\end{array}$ & $\begin{array}{c}0.518^{* *} \\
(0.084)\end{array}$ \\
\hline symbolic & $\begin{array}{c}1.279^{* *} \\
(0.082)\end{array}$ & & $\begin{array}{c}1.114^{* *} \\
(0.086)\end{array}$ \\
\hline value & $\begin{array}{l}0.164+ \\
(0.099)\end{array}$ & $\begin{array}{c}-1.114^{* *} \\
(0.086)\end{array}$ & \\
\hline manager $=1$ & $\begin{array}{c}0.029 \\
(0.059)\end{array}$ & $\begin{array}{c}0.029 \\
(0.059)\end{array}$ & $\begin{array}{c}0.029 \\
(0.059)\end{array}$ \\
\hline area $=1$ & $\begin{array}{c}0.725^{* *} \\
(0.064)\end{array}$ & $\begin{array}{c}0.725^{* *} \\
(0.064)\end{array}$ & $\begin{array}{c}0.725^{* *} \\
(0.064)\end{array}$ \\
\hline exposed=1 & $\begin{array}{l}0.699^{*} \\
(0.288)\end{array}$ & $\begin{array}{l}0.699^{*} \\
(0.288)\end{array}$ & $\begin{array}{l}0.699^{*} \\
(0.288)\end{array}$ \\
\hline shortened & & $\begin{array}{c}-1.279^{* *} \\
(0.082)\end{array}$ & $\begin{array}{r}-0.164+ \\
(0.099)\end{array}$ \\
\hline \multicolumn{4}{|l|}{ cut1 } \\
\hline Constant & $\begin{array}{c}1.826^{* *} \\
(0.070)\end{array}$ & $\begin{array}{c}0.547^{* *} \\
(0.049)\end{array}$ & $\begin{array}{c}1.661^{* *} \\
(0.073)\end{array}$ \\
\hline \multicolumn{4}{|l|}{ cut2 } \\
\hline Constant & $\begin{array}{c}2.781^{* *} \\
(0.083)\end{array}$ & $\begin{array}{c}1.503^{* *} \\
(0.050)\end{array}$ & $\begin{array}{c}2.617 * * \\
(0.086)\end{array}$ \\
\hline \multicolumn{4}{|l|}{ cut3 } \\
\hline Constant & $\begin{array}{c}3.282^{* *} \\
(0.075)\end{array}$ & $\begin{array}{c}2.004^{* *} \\
(0.058)\end{array}$ & $\begin{array}{c}3.118^{* *} \\
(0.095)\end{array}$ \\
\hline Observations & 7,561 & 7,561 & 7,561 \\
\hline
\end{tabular}




\subsection{Main analyses: Analysis of dosage effects}

Symbolic rewards vary greatly in their form and intensity - from low effort "thank you" messages to involved awards and ceremonies. At the time of writing there is no good evidence on potential dosage effects for symbolic rewards. Therefore, an exploratory hypothesis was added. The symbolic reward treatment was therefore split between a low and a higher dosage version. The low dosage involved only a "thank you", while the higher dosage communication invited bureaucrats to a workshop with one of the most senior ranking bureaucrats. It is expected that:

Hypothesis 1 Input that offers a reward which is more time and cost intensive will lead to greater engagement than a simple "thank-you".

After this main randomisation, individuals allocated to the symbolic treatment were randomised into a low or a high dosage condition. This was again stratified by the three variables identified above (managerial level, area of work and previous exposure).

To test for dosage effects, half of the symbolic reward emails included an additional sentence which invited them to a workshop to discuss their ideas while the other half did not.

The same balance checks as described in the main text were repeated to assess balance across the two different dosage conditions as part of the symbolic workshop. Gender was also balanced for these (Table 17).

Analyses suggest that the additional symbolic reward - an invitation - increases engagement significantly (Table 18). This suggests that there are dosage effects.

Based on conversations with local government staff and the internal staff consultation, the stronger dose version of the symbolic reward treatment offered staff to participate in a workshop because this was seen as a way that people commonly signalled value and status to others. In other organisational settings such an invitation might however be perceived differently. 
Table 17: Balance checks - dosage

\begin{tabular}{llll}
\hline \hline & $\begin{array}{l}\text { Treatment 2 } \\
\text { (Symbolic }- \text { no workshop) }\end{array}$ & $\begin{array}{l}\text { Treatment 2 } \\
(\text { Symbolic }- \text { workshop) }\end{array}$ & \\
& & & p-value \\
\hline Manager & $28.99 \%$ & $28.99 \%$ & 1.000 \\
Central & $19.68 \%$ & $19.79 \%$ & 0.954 \\
Prev. exposed & $0.63 \%$ & $0.85 \%$ & 0.592 \\
Gender & & $29.95 \%$ & 0.699 \\
Male & $30.79 \%$ & $70.05 \%$ & \\
Female & $69.21 \%$ & & \\
\hline \hline
\end{tabular}

Table 18: OLS regression with fixed effects for blocks - effects of dosage on engagement

\begin{tabular}{lll}
\hline \hline Explorative analysis & & \\
& $(1)$ & $(2)$ \\
& $\begin{array}{l}\text { Engagement (binary) } \\
\mathrm{b} / \mathrm{se}\end{array}$ & $\begin{array}{l}\text { Engagement (scale) } \\
\mathrm{b} / \mathrm{se}\end{array}$ \\
& & \\
\hline Higher dosage & 0.025 & $0.299^{* *}$ \\
& $(0.016)$ & $(0.048)$ \\
Manager & 0.048 & 0.129 \\
& $(0.019)$ & $(0.055)$ \\
Central & $0.137^{* *}$ & $0.400^{* *}$ \\
& $(0.025)$ & $(0.070)$ \\
Prev. exposed & 0.073 & 0.165 \\
& $(0.129)$ & $(0.368)$ \\
Constant & $0.100^{* *}$ & $0.308^{* *}$ \\
\hline & $(0.012)$ & $(0.036)$ \\
Observations & 1,890 & 1,890 \\
& & \\
\hline \hline$+\mathrm{p}<.008,{ }^{*} \mathrm{p}<.004,^{* *} \mathrm{p}<.001$ &
\end{tabular}


Table 19: Robustness check - OLS regression with fixed effects for blocks excluding sample treated with "workshop message"

\begin{tabular}{lc}
\hline \hline & $(1)$ \\
& $\begin{array}{c}\text { Engagement (scale) } \\
\mathrm{b} / \mathrm{se}\end{array}$ \\
\hline control & $-0.139^{* *}$ \\
& $(0.009)$ \\
symbolic & 0.021 \\
& $(0.015)$ \\
value & 0.011 \\
& $(0.012)$ \\
manager $=1$ & $0.020^{*}$ \\
& $(0.009)$ \\
area $=1$ & $0.121^{* *}$ \\
& $(0.012)$ \\
exposed $=1$ & 0.068 \\
& $(0.059)$ \\
Constant & $0.122^{* *}$ \\
& $(0.008)$ \\
\hline Observations & 6,616 \\
\hline \hline$+\mathrm{p}<0.1,{ }^{*} \mathrm{p}<0.05,{ }^{* *} \mathrm{p}<0.01$
\end{tabular}

It might not be the symbolic reward but the expectation that one needs to demonstrate that one has read the results at the workshop which causes bureaucrats to follow through. In an additional robustness check, I demonstrate that the effect of the symbolic reward remains large and significant if I omit the sub-sample who received the extra dose (Tables 3.7 and 3.7 .

\section{Budget analysis}

The main focus of the experiment were the immediate reactions of individual bureaucrats (see pre-registration details). Many decisions in the public sector however happen at the aggregate level: many people need to agree or influential individuals need to convince others for changes to take place. Similarly, if one individual bureaucrat might become more supportive of what citizens demand, changes might not be reflected in larger structures. However, if many bureaucrats within a work unit put pressure on senior leadership, changes are more likely to be enacted. Following this reasoning, one would expect that 


\begin{tabular}{lc}
\multicolumn{1}{c}{ Table 20: Robustness check - engagement (scale) } \\
\\
\hline \hline \\
& OLS regression with fixed effects for blocks: Engagement (scale) \\
& $\mathrm{b} / \mathrm{se}$ \\
\hline control & -0.007 \\
& $(0.022)$ \\
symbolic & $0.394^{* *}$ \\
& $(0.039)$ \\
value & $0.139^{* *}$ \\
& $(0.030)$ \\
manager $=1$ & 0.025 \\
& $(0.024)$ \\
area $=1$ & $0.329^{* *}$ \\
& $(0.032)$ \\
exposed $=1$ & $0.294+$ \\
& $(0.164)$ \\
Constant & $0.260^{* *}$ \\
& $(0.019)$ \\
\hline$R^{2}$ & 0.05 \\
Observations & 6,616 \\
\hline \hline$+\mathrm{p}<0.1,{ }^{*} \mathrm{p}<0.05,{ }^{* *} \mathrm{p}<0.01$ &
\end{tabular}

the larger the proportion of bureaucrats exposed to citizen input in a given local authority directorate, the more likely it is that this directorate tries to funnel funds towards addressing citizen priorities.

That noted, all local government budgets are constrained by the availability of funding from central government. Local government funds deriving from local taxes (so-called council taxes in the UK context) can be allocated more freely but make up only a tiny share of the overall budget. Analyses should therefore also account for the amount of central government funding available for each directorate. If there was responsiveness to citizen demands, one would expect (i) budget changes differ for priority compared to non-priority areas, (ii) budgets increased for priority areas (budget convergence) and that this is especially true for (iii) directorates in which a larger number of staff engaged with citizen input.

Decision-making in bureaucracies is collective and involves difficult trade-offs between technical and political considerations. Hierarchies result in some groups of bureaucrats having substantially more power over decisions at the organisational level than others. 
Table 21: Definition of budget outcome variables

\begin{tabular}{ll}
\hline Outcome & Variable definition \\
& $\Delta B_{s i}=B_{\text {sit }}+1-B_{\text {sit }}$ \\
Budget change & $\mathrm{s}$ is the key service areas within directorate \\
$\mathrm{k}$ in which bureaucrat i works \\
$\mathrm{t}+1$ is the next budget period, which follows after the experiment \\
which follows after the experiment
\end{tabular}

How much power individual bureaucrats yield over budgets is thus likely highly limited. What is more, local governments, such as the one under study, face the added difficulty that part of their budget is centrally determined and earmarked for certain purposes. While they can lobby for changes based on local needs, this is a long-term process and changes following citizen input are likely to be delayed and conflated with results achieved through electing politicians into central government who vouch for the same changes.

Bureaucrats can however build internal pressure by supporting (or opposing) alignment with citizen input.

These caveats noted, I look at two variables to gain a tentative understanding of how an increase in bureaucrats knowing about the preferences of their citizen-stakeholders might affect budget allocation: (i) changes in budget per key service area $(B)$ and (ii) whether these changes converge towards preferences expressed by the citizen input $(C)$.

Changes in budget $(B)$ are defined as the difference between budgets allocated at $t+1$ and in the budget period $t$ when the trial took place.

Citizens always requested more funding. Therefore, budget convergence $(C)$ is defined as: a binary variable defined as zero when budget in a key service area $s$ decreases between 
2018/19 $(t)$ and 2019/20 $(t+1)$. The variable is set to zero when budget for a priority area decreased or when budget increased and the area was not defined as a priority area. It is set to one when it increased for a priority area. As a robustness check, I run additional analyses with convergence set to one also when non-priority areas experience cuts.

The multi-stakeholder nature of budget decisions means that we can only look at correlation between changes in budgets and priorities voiced by citizens. As Table ?? shows, budget changes were only responsive to citizen demands in two our of five areas: funding as increased for the directorates dealing with the environment (parks, green spaces, roads) and economic growth strategies (business support, employment). 
Table 22: Overview - budget changes by directorates, priority areas and treatment conditions

\begin{tabular}{|c|c|c|c|c|c|c|c|c|}
\hline $\begin{array}{c}\text { Budget } \\
\text { convergence }\end{array}$ & $\begin{array}{l}\text { Service } \\
\text { budget }\end{array}$ & $\begin{array}{l}\text { Directorate } \\
\text { yes/no }\end{array}$ & $\begin{array}{c}\text { Citizen } \\
\text { priority }\end{array}$ & Directorate & $\begin{array}{l}\text { Proportion of staff } \\
\text { who looked at info }\end{array}$ & $\begin{array}{c}\text { Shortened - } \\
\text { looked }\end{array}$ & $\begin{array}{l}\text { Value - } \\
\text { looked }\end{array}$ & $\begin{array}{c}\text { Symbolic - } \\
\text { looked }\end{array}$ \\
\hline no & $-281,000$ & Education Lifelong Learning Culture & yes & Children, & \multirow{6}{*}{$4.8 \%$} & \multirow{6}{*}{$9.0 \%$} & \multirow{6}{*}{$9.1 \%$} & \multirow{6}{*}{$1.3 \%$} \\
\hline $\mathrm{n} / \mathrm{a}$ & $-6,300$ & Quality Assurance & no & Learning, & & & & \\
\hline no & $-44,300$ & Family Resilience & yes & Families, & & & & \\
\hline $\mathrm{n} / \mathrm{a}$ & $-95,000$ & Corporate Parenting & no & Culture, & & & & \\
\hline $\mathrm{n} / \mathrm{a}$ & $\mathrm{n} / \mathrm{a}$ & Delegated Schools & no & & & & & \\
\hline $\mathrm{n} / \mathrm{a}$ & $-13,000$ & Commissioning & no & & & & & \\
\hline $\mathrm{n} / \mathrm{a}$ & $-1,000$ & Cross County Transformational Savings & no & Customer, & \multirow{9}{*}{$17.5 \%$} & \multirow{9}{*}{$31.8 \%$} & \multirow{9}{*}{$32.2 \%$} & \multirow{9}{*}{$10.1 \%$} \\
\hline $\mathrm{n} / \mathrm{a}$ & 700 & Joint Operating Budget ORBIS & no & Digital Transformation & & & & \\
\hline $\mathrm{n} / \mathrm{a}$ & 140 & Customer Services & no & & & & & \\
\hline $\mathrm{n} / \mathrm{a}$ & -200 & Communications & no & & & & & \\
\hline $\mathrm{n} / \mathrm{a}$ & 70 & Information Technology Digital & no & & & & & \\
\hline $\mathrm{n} / \mathrm{a}$ & 170 & Coroner & no & & & & & \\
\hline $\mathrm{n} / \mathrm{a}$ & -60 & Strategy Performance & no & & & & & \\
\hline $\mathrm{n} / \mathrm{a}$ & 600 & Strategic Leadership & no & & & & & \\
\hline $\mathrm{n} / \mathrm{a}$ & 90 & Human Resources Organisational Development & no & & & & & \\
\hline $\mathrm{n} / \mathrm{a}$ & 300 & Property & no & Economy, & \multirow{6}{*}{$7.6 \%$} & \multirow{6}{*}{$13.7 \%$} & \multirow{6}{*}{$13.6 \%$} & \multirow{6}{*}{$3.1 \%$} \\
\hline $\mathrm{n} / \mathrm{a}$ & $\mathrm{n} / \mathrm{a}$ & Procurement & no & Growth, & & & & \\
\hline $\mathrm{n} / \mathrm{a}$ & 30 & Business Operations & no & Commercial & & & & \\
\hline $\mathrm{n} / \mathrm{a}$ & 30 & Legal Services & no & & & & & \\
\hline $\mathrm{n} / \mathrm{a}$ & 30 & Democratic Services & no & & & & & \\
\hline yes & 10 & Economic growth & yes & & & & & \\
\hline $\mathrm{n} / \mathrm{a}$ & -2000 & Corporate expenditure & no & Finance Corporate & $12.4 \%$ & $24.5 \%$ & $19.3 \%$ & $4.6 \%$ \\
\hline no & -6000 & Adults Social Care & yes & Health, & $6.5 \%$ & $9.3 \%$ & $13.9 \%$ & $2.8 \%$ \\
\hline $\mathrm{n} / \mathrm{a}$ & 0 & Public Health & no & $\begin{array}{c}\text { Wellbeing, } \\
\text { Adult Social Care }\end{array}$ & $6.5 \%$ & $9.3 \%$ & $13.9 \%$ & $2.8 \%$ \\
\hline $\mathrm{n} / \mathrm{a}$ & 10 & Trading Standards & no & Highways, & \multirow{7}{*}{$7.8 \%$} & \multirow{7}{*}{$15.4 \%$} & \multirow{7}{*}{$13.8 \%$} & \multirow{7}{*}{$2.4 \%$} \\
\hline no & $-6,000$ & Highways Transport & yes & Transport, & & & & \\
\hline $\mathrm{n} / \mathrm{a}$ & $\mathrm{n} / \mathrm{a}$ & Directorate-wide savings & no & Environment & & & & \\
\hline $\mathrm{n} / \mathrm{a}$ & -10 & Emergency Management & no & & & & & \\
\hline $\mathrm{n} / \mathrm{a}$ & 1,000 & Fire Rescue Service & no & & & & & \\
\hline yes & 1100 & Environment & yes & & & & & \\
\hline $\mathrm{n} / \mathrm{a}$ & -100 & Communities Support function & no & & & & & \\
\hline $\mathrm{n} / \mathrm{a}$ & 0 & Transformation Programme & no & $\begin{array}{c}\text { Customer, } \\
\text { Digital Transformation }\end{array}$ & $17.5 \%$ & $31.8 \%$ & $32.2 \%$ & $10.1 \%$ \\
\hline
\end{tabular}




\section{Intervention materials}

\subsection{CONTROL}

Subject line: Results of resident and partner engagement on [local authority] Vision [future year]

Dear Test Name,

As you are aware we have recently concluded an engagement exercise with residents, partners and staff to get their views on a new vision for [local authority] [future year]. This is the most systematic and extensive engagement exercise among residents and partners we have ever done with over [number $i 2,000]$ partners and residents sharing their views. I wanted to update you on the feedback.

We will use these insights to shape a more efficient [local authority] that uses its resources wisely to meet the needs of residents.

In brief, the things that people value about [local authority] are:

1. Advantages offered by its location

2. Mix of urban and rural life, in particular green spaces and the countryside

3. Low levels of crime

4. Access to good quality public services

5. Strong sense of community spirit fostered by caring, supportive and friendly people

6. Strength of the economy, with low unemployment and thriving independent local businesses

However, there are things that need to be improved. Residents and partners both agree that the focus areas for the future are housing, infrastructure - including transport sustainability of public services / cuts and ensuring no one gets left behind. Additionally 
residents also identified environment and crime as focus areas whilst partners would like earlier intervention / prevention and better quality partnerships.

A full report of the findings including experiences and ideas from residents and partners is available on [intranet name] here:

\section{$[\mathrm{LINK}]$}

What this means for us as a council?

1. To help deliver this we need to be a well-run and stable council with a focus on improving the lives of people who can't look after themselves and who could otherwise be left behind.

2. We will work alongside others to enable residents and businesses to be as successful as possible and for people to live fulfilled and healthy lives.

3. With less income and more demand, we will need to transform our way of working and do better for less. We will do fewer things and we will do them better. In the coming weeks we will be sharing a new vision based on the feedback and how we can all work together better to deliver a sustainable council and county for all. Do look out for updates on [intranet name] and Jive[local authority].

[senior signature]

Executive Director for Customers, Digital and Transformation 


\subsection{SHORTENED}

Subject line: Results of resident and partner engagement on [local authority] Vision [future year]

Dear Test Name,

We want to share the results of an engagement exercise on the [local authority] Vision [future year] with you.

Over the summer of 2018, [the local authority] carried out the most systematic and extensive engagement exercise of residents and partners it has ever done to get their views on a new vision for [local authority] to [future year]. In total more than [number ¿2,000] people have provided their views.

Some of the things they said they valued were safety, green spaces and easy commutes. They also told us that they are worried about housing and the sustainability of quality care.

We would like to encourage you to learn more about what residents and partners thought here on [intranet name]:

[LINK]

We would like you to think about how you could use these insights for your work, to shape a [local authority] that uses its resources wisely to meet the needs of residents.

[senior signature]

Executive Director for Customers, Digital and Transformation 


\subsection{VALUE}

Subject: Views from the people you care about - [local authority] Vision [future year]

Dear Test Name,

We know you care deeply about the people you serve through your work every day. We want to share with you what they value about [local authority] and what they would like to change.

Over the summer of 2018, [the local authority] carried out the most systematic and extensive engagement exercise of residents and partners it has ever done to get their views on a new vision for [local authority] to [future year]. In total more than [numer ¿2,000] people have provided their views.

Some of the things they said they valued were safety, green spaces and easy commutes. They also told us that they are worried about housing and the sustainability of quality care.

We would like to encourage you to learn more about what people thought here on the [intranet name]:

\section{[LINK]}

We would like you to think about how you could use these insights for your work, to shape a [local authority] that uses its resources wisely to meet the needs of residents.

[senior signature]

Executive Director for Customers, Digital and Transformation 


\subsection{SYMBOLIC REWARDS}

Subject Line: Thank you for your effort in making LocalGovName a great place LocalGovName Vision YEAR

Dear Test Name,

We would like to thank you for the effort you have put in to make LocalGovName a great place to live. We want to share with you what they value about LocalGovName and what they would like to change.

Over the summer of 2018, LocalGovName County Council carried out the most systematic and extensive engagement exercise of residents and partners it has ever done to get their views on a new vision for LocalGovName to YEAR. In total more than 2,300 people have provided their views.

Some of the things they said they valued were safety, green spaces and easy commutes. They also told us that they are worried about housing and the sustainability of quality care.

We would like to encourage you to learn more about what people thought here on the s-net:

\section{$[\mathrm{LINK}]$}

We would like you to think about how you could use these insights for your work, to shape a LocalGovName that uses its resources wisely to meet the needs of residents.

[senior signature]

Executive Director for Customers, Digital and Transformation 


\section{Randomisation code}

Below you can find the $\mathrm{R}$ code used for the block randomisation of email addresses into different treatment groups, blocked by managerial status, work location and previous exposure to the citizen input. It uses the R-package randomizr. For anonymised replication data and all analysis code used for this paper, please consult the OSF/SocArxiv data repository associated with this paper.

library(randomizr)

GET files with all details files ;- data.frame(read.csv( "LOCAL DRIVE"))

Get file with list of people who have been exposed to the info before pre.exposed i- data.frame(read.csv("LOCAL DRIVE"))

Merge the two files i- merge( files, pre.exposed[,c("ID","Exposed")], by="ID", all.x=TRUE)

id - filesIDtrue $<-$ sapply (files, is.numeric)data $<-$ apply(files[!true], 2, tolower)data $<-$ data.frame $($ data $) N<$ -length(filesPersonnel.Area) data $I D<-i d$

Mark emails that belong to people who are senior decision makers datamanager $<-r e p(0, N)$ datamanager[regexpr('manager', dataOrg.Unit.Position.Name) >0|regexpr ('snr', dataOrg.Unit.Position.Name )¿0 - regexpr('senior', dataOrg.Unit.Position.Name) > $0 \mid($ regexpr ('exec', dataOrg.Unit.Position.Name)¿0 regexpr('assistant', dataOrg.Unit.Position.Name) $==0)]<-1$

Mark emails that are of people who work in office-based jobs in central LA(ANON) CC dataarea $<-$ rep $(0, N)$ dataarea[regexpr('county hall', dataBuilding.Location.Desc) $>0]<-1$

Mark people who should not receive emails because they have shared accounts or are not on a permanent contract filesRemoved [is.na(filesRemoved)] i- 0 dataremoved $<-$ filesRemoved

Mark people who have been exposed to the info before filesExposed[is.na(filesExposed)] $\mathrm{i}^{-} 0$ dataexposed $<$ -filesExposed

Block randomise people who should receive emails data $\mathbf{i}$ - data.frame $($ data $[, \mathrm{c}(1: 8,10: 14)])$ data.receive $\mathbf{i}-$ data $[$ which $($ dataremoved $==$

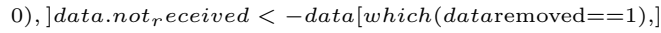

blocks i- as.numeric(factor(paste0( data.receivemanager, data.receivearea, data.receiveexposed)) 1-4Nomanager, 3478arecentralLA(ANON)CC, ev

Email.Type i- block $_{r} a($ blocks, numarms $=4$, conditions $=$ c("control", "shortened", "value", "symbolic"))

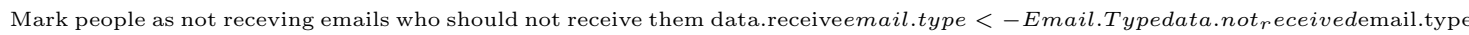
$i^{-}$"none"

Put the two together again data.all $\boldsymbol{i}$ - data.frame(rbind(data.receive, data.not ${ }_{r}$ eceived))

Block randomise those who receive the symbolic reward treatment into receiving a workshop or not data.symbolic i-

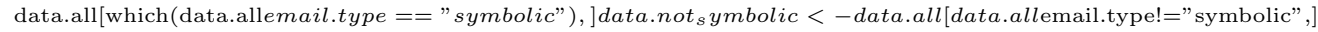

blocks.symbolic i- as.numeric(factor(paste0(data.symbolicmanager, data.symbolicarea, data.symbolicexposed)))1 4 Nomanager, 3478 arecentralL $A(A N O N) C C$, every2ndexposed

Workshop i- block$_{r}$ a(blocks.symbolic, numarms $=2$, conditions $=$ (" "noworkshop", "workshop"))data.symbolicworkshop

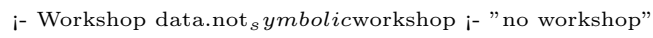

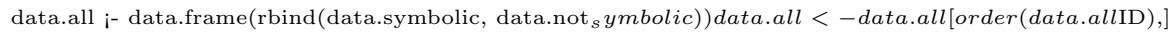

write.csv(data.all, "LOCAL DRIVE")

Double check whether randomised correctly table(data.allemail.type, data.allworkshop)

table(data.allemail.type, data.allremoved)

table(data.allemail.type, data.allmanager)

table(data.allemail.type, data.allarea)

table(data.allemail.type, data.allexposed) 


\section{References}

Lipsky, M. (1983). Street-Level Bureaucracy The Dilemmas of the Individual in Public Service. Publications of Russell Sage Foundation Street-level bureaucracy. New York: Russell Sage Foundation. 